\author{
UNIVERSIDADE DE SÃO PAULO \\ FACULDADE DE ZOOTECNIA E ENGENHARIA DE ALIMENTOS
}

ARIANE MARIA LEONI

Formulação de rações para frangos de corte com o uso da programação linear e não linear

Pirassununga

2016 
Formulação de rações para frangos de corte com o uso da programação linear e não linear

\author{
Versão corrigida
}

Dissertação apresentada à Faculdade de Zootecnia e Engenharia de Alimentos da Universidade de São Paulo, como parte dos requisitos para obtenção do Título de Mestre em Zootecnia

Área de Concentração: Qualidade e Produtividade Animal

Orientador: Prof. Dr. Daniel Emygdio de Faria Filho

\title{
Pirassununga
}


Ficha catalográfica elaborada pelo

Serviço de Biblioteca e Informação, FZEA/USP,

com os dados fornecidos pelo(a) autor(a)

Leoni, Ariane Maria

L585f Formulação de rações para frangos de corte com o uso da programação linear e não linear. / Ariane Maria Leoni ; orientador Daniel Emygdio de Faria Filho. - Pirassununga, 2016.

$43 \mathrm{f}$.

Dissertação (Mestrado - Programa de Pós-Graduação em Zootecnia) -- Faculdade de Zootecnia e Engenharia de Alimentos, Universidade de são Paulo.

1. Programação não linear. 2. Modelos matemáticos. 3. Nutrição animal. 4. Alimentação animal. 5. Frangos de corte. I. Faria Filho, Daniel Emygdio de, orient. II. Título. 


\title{
ARIANE MARIA LEONI
}

\section{Formulação de rações para frangos de corte com o uso da programação linear e não linear}

Dissertação apresentada à Faculdade de Zootecnia e Engenharia de Alimentos da Universidade de São Paulo, como parte dos requisitos para obtenção do Título de Mestre em Zootecnia

Área de Concentração: Qualidade e Produtividade Animal

Data de aprovação:

Banca Examinadora:

\author{
Prof. Dr. Daniel Emygdio de Faria Filho \\ Universidade de São Paulo
}

Profa. Dra. Catarina Abdalla Gomide

Universidade de São Paulo

Profa. Dra. Cristiane Soares da Silva Araújo

Universidade de São Paulo

Profa. Dra. Janaína Della Torre da Silva

Universidade Federal de São Carlos 
A meu pai, Angelo Leoni (in memoriam). Pai, "sua presença sempre se fará sentir, pois o brilho do seu exemplo permanecerá iluminando o meu caminho."

A minha mãe, Tereza A. M. Leoni, que se doou por inteiro e, muitas vezes, renunciou aos próprios sonhos para que eu pudesse realizar os meus, minha eterna gratidão."

Amo vocês. 


\section{AGRADECIMENTOS}

A Deus, que me deu a vida, meu agradecimento especial. Obrigada, Senhor, por me acompanhar em todos os meus caminhos. É a Deus a quem primeiro ofereço esta conquista e a Ele confio todos os meus passos e minha profissão.

A meus pais, Angelo (in memorian) e Thereza, pelo amor e dedicação na minha educação e por me ensinarem a viver com dignidade, respeito e lealdade e a construir honestamente a minha história. E, também, pela herança dos sentimentos de gratidão diante das conquistas e encorajamento nas dificuldades, sem desistir, jamais, dos meus sonhos.

A meu orientador de pesquisa, Prof. Dr. Daniel Emygdio de Faria Filho, meu profundo respeito e minha gratidão pela confiança, apoio e orientação. E por se fazer ponte, me encorajar a atravessar e, depois, tendo facilitado minha travessia, desmoronou-se com prazer, incentivandome a criar minhas próprias pontes.

Aos demais professores que transmitiram seus conhecimentos e experiências profissionais com dedicação, ganhando de mim respeito. Que nunca deixem de ensinar, de treinar, de aprender e de lutar por compreender, cada vez melhor, o perfeito e invisível princípio de toda a vida.

À FAPESP, Fundação de Amparo à Pesquisa do Estado de São Paulo, pelo apoio financeiro (processo $n^{\circ}$ 2014/01573-7), primordial para a realização da pesquisa.

À Faculdade de Zootecnia e Engenharia de Alimentos da Universidade de São Paulo, campus de Pirassununga, pela valiosa oportunidade oferecida para o aprimoramento do meu conhecimento.

Ao Cláudio, por compartilhar seus ensinamentos e suas experiências, com dedicação e paciência, fundamentais para o êxito da minha pesquisa de campo, minha gratidão, meu respeito e minha amizade. 
Aos colegas de pesquisa, Bárbara, Bruna, Julian, Márcio e Renan, pela colaboração, compreensão e solicitude durante a condução do experimento. E, em especial, à Amanda e Ana Paula pela atenção, dedicação e empatia durante a pesquisa, tornando possível a conclusão desta etapa.

A meus "irmãos de mestrado", Rogério, pelo constante apoio, passando-me tranquilidade e coragem nos momentos críticos e também pelas boas e alegres conversas e Thiago, pela atenção, ensinamentos e, principalmente, por me fazer acreditar que, ao final, tudo daria certo.

Às estagiárias Érica e Nayara, pela dedicação, presteza, interesse e carinho durante os cuidados no aviário experimental.

Ao Márcio Tadeu Tomazela Lima, pela paciência e presteza, dedicando parte de seu tempo, transmitindo suas experiências. E ao Msc. Waldomiro Barioni Júnior, por compartilhar, com humildade e sabedoria, seus valiosos ensinamentos para a compreensão desta pesquisa.

À Maria Angélica, pela valiosa presença e profissionalismo em casa, durante minhas ausências, meu carinho e minha gratidão.

Jamais serei suficientemente grata àqueles que, de alguma forma, com dedicação e simplicidade, contribuíram para a realização deste trabalho. 
"Os gregos, que nos legaram cabedal sublime no ramo do saber, ao contemplarem a organização existente no mundo, chamaram-no de COSMOS, a saber, harmonia. Realmente, do universo micro ao macro, se constata que tudo procede como excepcional orquestra regida por maestro não menos dotado. É de o cientista descobrir tais tesouros para que os tenhamos adaptados ao bem comum.

Os latinos, por sua vez, também ao contemplarem a harmonia e a beleza do cosmos as chamaram de MUNDO, que significa puro. Afinal, o que não é mundo é imundo, não mundo, não puro: impuro.

As Escrituras refletem o existente sob o aspecto ético e afirmam: "tudo o que foi criado é bom" (Gn 1,1-2,4) e procede da BONDADE. Mas constatam que, em tanta harmonia, em tanta pureza e bondade, penetrou o mal e lutam para extirpá-lo e para transformar os pecadores em santos. Constatamos que, ao menos a partir de Pasteur, a geração espontânea ou abiogênese, recebeu golpe mortal. Como nada vem do nada, a harmonia a pureza e a santidade pedem a existência do Harmonizador, do Purificador e do Santificador que são o parâmetro e a razão de ser do que existe e se agita no universo. Insistamos: do que se agita ordenadamente no universo não racional.

Tudo nos leva a acatar a existência do Big Bang, a grande explosão cósmica da qual se originaram maravilhas: energia portentosa se expande e vai concretizando potencialidades inerentes. O primeiro fruto foi o surgimento da matéria inanimada: os metais, os cristais... Da materialidade foram surgindo seres vivos que vegetavam em sua materialidade. Destes, paulatinamente foi eclodindo a sensibilidade; animais de maior ou menor porte. Eras depois, o mundo se abriu para seres que na materialidade, na "vegetalidade" e na sensibilidade foram se abrindo para a racionalidade. Surgiu, então, o rei da criação, o ser humano dotado do noético, ético e estético.

Pela noese, a criatura humana se abre aos segredos da natureza, do micro ao macro cosmos, desvendando mistérios e mais mistérios. Essa conquista revela a riqueza do mundo que vai sendo conquistado e adaptado pelos humanos segundo suas necessidades. A sucessão de conquistas pega de surpresa até mesmo pessoas atentas e atualizadas. Mas, lamentavelmente, tanta potencialidade noética é coloca, também, ao serviço do mal, da destruição, da opressão, da exploração.

Pari passu, a criatura racional é dotada, como se falou, com outra riqueza: a estética. Por ela, os humanos ficam possibilitados de admirar o belo: o ocaso, a aurora, as flores, o canto e as cores dos pássaros. Por ela, eles não só admiram as belezas existentes, como se tornam capazes de criá-las. Surgem as artes: música, poesia, esculturas, pinturas, que são recursos que plasmam a sensibilidade humana. O belo existente (fores, pássaros...), ou criados pelos poetas, pintores, músicos e escultores são meios riquíssimos de humanização.

Agora, o que dizer do ético? A criatura racional se vê aberta, ilimitadamente, para o bem. Para sermos mais precisos, aberto à Bondade que não é mero ser abstrato; tanto que usamos a "B" maiúsculo. Antagonicamente ao bem, se coloca o mal. E nós nos colocamos entre estes dois extremos em luta sem quartel. Ao menos os que procuram se conhecer e se possuir harmoniosamente. Nestes extremos antagônicos, tanto podemos atingir os arcanos da divindade como a mais degradante vileza da criminalidade.

Parágrafos atrás lembramos que, fruto do Big Bang, o ser humano é a coroa da criação. $O$ processo evolutivo o galgou a patamares distinguidos. Sua perfectibilidade parou? Somente para estar onde está. O processo evolutivo, agora, não se abre para mais nada? Existiria um 
onde melhor, um "Alguém infinito"? Qual é a função humana no Big Bang para não encarálo "automatizado"em sua força evolutiva? Não nos caberia, agora, enriquecendo-o pela nossa razão e com tudo o que ela acarreta, dar-lhe sentido ao evoluir-se ao infinito? Este é o objetivo da criatura racional.

Estes prolegômenos são para tecer algumas considerações sobre o trabalho de Ariane Maria Leoni. Suas investigações estão essencialmente vinculadas a ela como estudiosa prendada.

Insistamos: ela é uma pessoa de fé. Sabe, como cientista descobrir as leis da natureza. Mas ela vai além: procura comungar e dialogar com o Autor do mundo, o "Alguém" que o plasmou, bem como as leis que o regem, a começar pelas da Big Bang. Com isso, Ariane adentra-se pelos campos da ética e da noética.

Mas ela é, ainda, enamorada e defensora da natureza, sobremaneira das aves, com destaque às silvestres. Nelas descobre a beleza das plumagens, dos cânticos, e a perspicácia de cada uma. Então, também a estética é parte integrante de seu ser. Sabe que essas aves não estão simplesmente para alegrar o coração humano com suas plumagens, com os seus cânticos. Sabe, ainda, como cada uma delas é útil controlando a proliferação de insetos ou vermes daninhos, como ajudando na fecundação das plantas. Quem ignora o "trabalho" indispensável da gralha azul, a semeadora de pinheirais?

Para melhor retratarmos sua alma estética e ética, colhemos a voz do poeta e do orante que se faz presente na beleza e no fervor da poesia que fala do Criador e das criaturas.

Por brevidade, ela vai truncada:

$$
\begin{gathered}
\text { "O grande Autor da terra, } \\
\text { que, as águas repelindo, } \\
\text { do mundo o solo erguestes, } \\
\text { a terra produzindo, }
\end{gathered}
$$

de plantas revestidas, ornadas pelas flores, e dando muitos frutos, diversos em sabores.

Deus de supremo poder, Da água os seres gerastes Com uns enchestes os mares, De outros o ar povoastes.
Uns mergulhastes nas águas, Outros soltastes no ar, Com o impulso que os leva A toda a terra ocupar.

Deus, escultor do homem, Que a tudo, só criastes, e que do pó da terra os animais formastes.

Sob o comando do homem A todos colocastes, Para que a vós servissem Servindo a quem criastes".

Ariane, porém, não é radical. Sabe respeitar a beleza, a utilidade das aves, mas reconhece que elas estão a serviço dos humanos. As qualidades de nossa pesquisadora estão patenteadas no texto acessível a todos os leitores. Testou número não acanhado de pintainhos da mesma idade, colocando-os em diversas situações diferenciadas. Os seis blocos propiciam confrontos iluminadores. A leitura do trabalho ilustrará mais do que nossas palavras de leigo.

Queremos destacar que Ariane, mesmo "instrumentalizando" os frangos, colocando-os à disposição da humanidade, tudo faz para que as aves sejam tratadas com o merecido respeito. Parabenizando nossa investigadora, formulamos votos para que sua carreira acadêmica seja brilhante. Quer para o bem da ciência, quer da humanidade, quer para as aves. E, de modo especial, para Ariane." 


\section{RESUMO}

\section{LEONI, A. M. Formulação de rações para frangos de corte com o uso da programação}

linear e não linear. 2016. 43 f. Dissertação - Faculdade de Zootecnia e Engenharia de Alimentos, Universidade de São Paulo, Pirassununga, 2016.

O objetivo deste estudo foi avaliar o efeito de formulações de rações para frangos de corte utilizando programação linear e não linear sobre desempenho, características de carcaça e aspectos econômicos. Um mil e oitenta machos da linhagem Cobb $500^{\mathrm{TM}}$, com um dia de idade, foram distribuídos em delineamento em blocos casualizados, com seis tratamentos e seis repetições de 30 aves cada. Os tratamentos foram: 1) ração formulada por programação linear com exigência nutricional das Tabelas Brasileiras para Aves e Suínos; 2) ração formulada por programação linear com exigência nutricional do Manual de Manejo Cobb $^{\mathrm{TM}}$; 3) ração formulada por programação linear com exigência nutricional de modelos matemáticos; 4) ração formulada por programação não linear em cenário normal de mercado; 5) ração formulada por programação não linear em cenário favorável de mercado; e 6) ração formulada por programação não linear em cenário desfavorável de mercado. Considerou-se cenário de mercado normal os valores do milho, do farelo de soja e do preço pago pelo kg de frango vivo em 26/03/2015, para o interior do Estado de São Paulo. Para o cenário favorável, os valores dos ingredientes baixaram $10 \%$ e o preço pago pelo kg de frango vivo subiu $10 \%$ e, para o cenário desfavorável, ocorreu o inverso. Foram avaliadas as características de desempenho e econômicas aos 21 e 42 dias de idade e também as características de carcaça aos 42 dias. Os dados foram submetidos à análise de variância e, em caso de significância $(\mathrm{P}<0,05)$, aplicou-se o teste de Scott-Knott (5\%). Os melhores resultados de desempenho e de características de carcaça foram associados aos tratamentos oriundos da programação linear, cujas concentrações de nutrientes foram mais elevadas, dos quais proteína bruta, aminoácidos e fósforo disponível são determinantes do desempenho superior de frangos de corte. Os tratamentos oriundos da programação não linear geraram melhores resultados econômicos, principalmente no cenário de mercado favorável, que apontou o menor custo para produção de $1 \mathrm{~kg}$ de peso corporal e maior lucro. Conclui-se que a formulação de ração com o uso da programação não linear, embora não maximize o desempenho, possibilita a obtenção de rações que otimizam o lucro.

Palavras-chave: Avicultura. Metanálise. Modelagem matemática. Nutrição de precisão. Retorno decrescente. 


\begin{abstract}
LEONI, A. M. Feed formulation for broilers using linear and nonlinear programming. 2016. 43 p. M.Sc. Dissertation - Faculdade de Zootecnia e Engenharia de Alimentos, Universidade de São Paulo, Pirassununga, 2016.

The aim of this study was to evaluate the effect of feed formulations for broilers using linear and nonlinear programming on performance, carcass characteristics and economic aspects. One thousand and eighty, one-day-old male broilers, Cobb 500 тм strain, were distributed in a randomized block design, with six treatments and six replicates of 30 birds each. The treatments were: 1) feed formulated by linear programming with nutritional requirement of the Brazilian Tables for Poultry and Swine; 2) feed formulated by linear programming with nutritional requirement of Management $\mathrm{Cobb}^{\mathrm{TM}}$ Manual; 3) feed formulated by linear programming with nutritional requirement of mathematical models; 4) feed formulated by nonlinear programming on normal market scenario; 5) feed formulated by nonlinear programming on favorable market scenario; and 6) feed formulated by nonlinear programming on unfavorable market scenario. In the normal market scenario values of corn, soybean meal and the price paid for $\mathrm{kg}$ of live broiler were that practiced on March 26, 2015, for the state of São Paulo. To the favorable scenario, the values of the ingredients decreased $10 \%$ and the price paid for $\mathrm{kg}$ of live broiler increased by $10 \%$ and, for the unfavorable scenario, the opposite happened. The performance and economic characteristics at 21 and 42 days, and carcass characteristics at 42 days were evaluated. Data were submitted to analysis of variance and, in case of significance $(\mathrm{P}<0.05)$, the Scott-Knott test (5\%) were applied. Best performance and carcass characteristics results were associated with treatments derived from linear programming, whose nutrient concentrations were higher, of which crude protein, amino acids and available phosphorus are determining the superior performance of broilers. Treatments arising from the non-linear programming generated better economic results, especially in the favorable market scenario, which showed the lowest cost to produce $1 \mathrm{~kg}$ of body weight and higher profit. It was concluded that feed formulation using non-linear programming, even though does not maximize performance, allows to feed formulation that optimize profit.
\end{abstract}

Keywords: Diminishing returns. Mathematical modeling. Meta-analysis. Poultry. Precision Nutrition. 


\section{SUMÁRIO}

\section{CAPÍTULO 1}

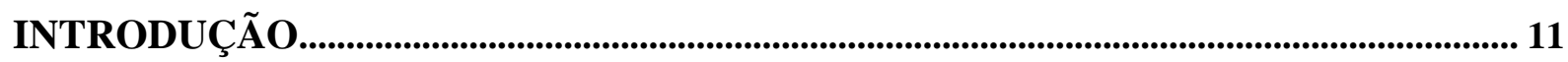

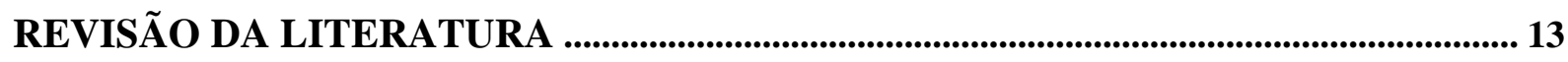

Programação linear para formulação de rações ................................................................. 13

Programação não linear para formulação de rações ............................................................ 15

Revisão sistemática da literatura e metanálise ………………………………………….... 17

Pesquisas de formulação de ração utilizando programação não linear ................................... 18

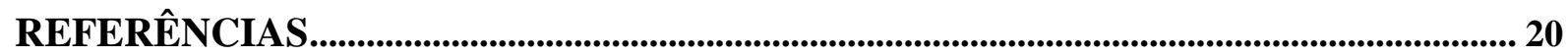

\section{CAPÍTULO 2}

FORMULAÇÃO DE RAÇÕES PARA FRANGOS DE CORTE USANDO

PROGRAMAÇÃ̃ LINEAR E NÃO LINEAR ........................................................................... 24

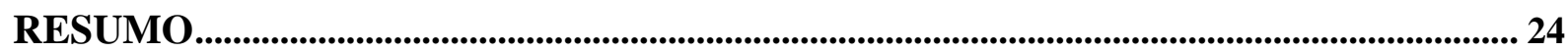

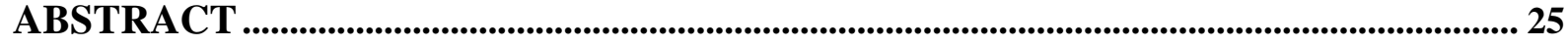

IMPLICAÇÕES .......................................................................................................................................... 26

INTRODUÇÃO ............................................................................................................................. 26

MATERIAL E MÉTODOS....................................................................................2

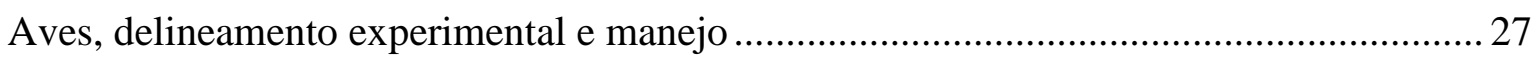

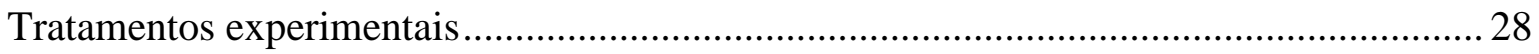

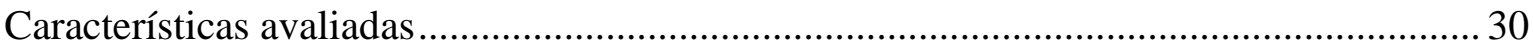

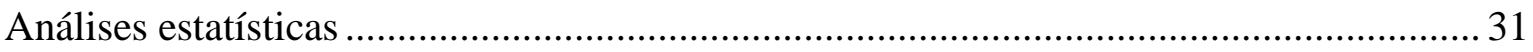

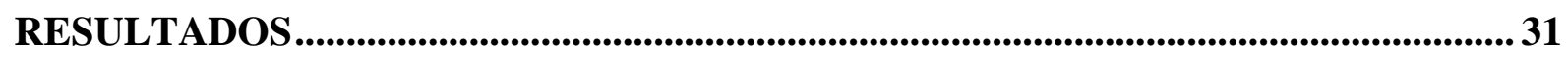

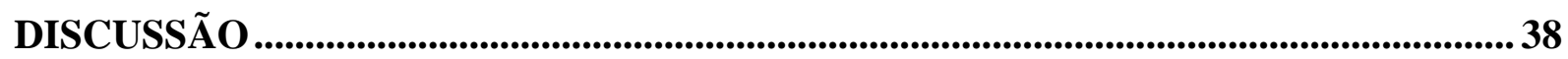

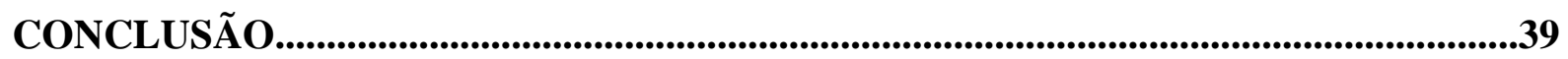

REFERÊNCIAS.................................................................................................................... 40

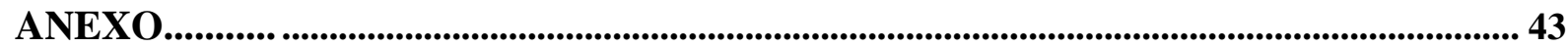




\section{CAPÍTULO 1}

\section{INTRODUÇÃO}

A carne de frango está presente em mais de 150 países. Em relação ao mercado mundial, em 2015 os Estados Unidos da América lideraram a produção com 17,966 milhões de toneladas, seguidos do Brasil com 13,146 milhões de toneladas e da China com 13,025 milhões de toneladas. Referente à exportação, no mesmo ano, o Brasil ocupou a primeira posição mundial com 4,304 milhões de toneladas, seguido pelos Estados Unidos da América com 2,990 milhões de toneladas e pela União Europeia com 1,150 milhões de toneladas. Dessa forma, aproximadamente $67,26 \%$ da produção de carne no Brasil é destinada ao mercado interno, sendo o restante exportado. O consumo per capita no Brasil, em 2015, foi de 43,25 kg por habitante (ASSOCIAÇÃO BRASILEIRA DE PROTEÍNA ANIMAL - ABPA, 2016).

A ração representa a maior parte do custo de produção de frangos de corte. De 2007 a 2012, no Brasil, o custo com alimentação oscilou de 53 a $71 \%$ do custo total (AVISITE, 2012). Em fevereiro de 2016, no estado do Paraná, 72,6\% do custo total da produção de frangos de corte foi com alimentação (CENTRO DE ESTUDOS AVANÇADOS EM ECONOMIA APLICADA - CEPEA, 2016). Dessa forma, a alimentação é o fator que mais onera o custo de produção, sendo importante a adoção de técnicas de formulação de ração que permitam a maximização do lucro no empreendimento avícola.

Rações podem ser formuladas com utilização da programação linear, que tem por objetivo minimizar o custo da ração (NABASIRYE et al., 2011), priorizando-se o máximo desempenho que é determinado pelo método dose-resposta (SAKOMURA; ROSTAGNO, 2007). Esse sistema é o mais difundido na indústria avícola e utiliza, para a formulação, o preço e a composição nutricional dos ingredientes, bem como informações sobre as exigências nutricionais (ZHANG; ROUSH, 2002; VIEIRA; STEFANELLO; SORBARA, 2014). Nesse caso, encontra-se uma mistura de ingredientes que atenda a exigência nutricional com o menor custo possível. No entanto, por meio da programação linear, não é possível predizer os efeitos da variação dos níveis nutricionais sobre o desempenho e rendimento de carcaça, ficando, assim, inviabilizadas as análises econômicas precisas (OVIEDO-RONDÓN; WALDROUP, 2002; PEÑA; LARA; CASTRODEZA, 2009).

A máxima lucratividade é atingida quando se obtém a exigência nutricional conforme a variação dos cenários de mercado, princípio da formulação por programação não linear de 
rações (ALMQUIST, 1953; GOUS, 1998; GUEVARA, 2004). Para viabilizar essa técnica, metodologias de otimização não lineares são utilizadas com o propósito de determinar, durante a formulação da ração, as exigências nutricionais para maximização da lucratividade, que, por sua vez, dependem das variações dos custos da ração, do preço pago pelo frango vivo e do desempenho obtido (CERRATE E WALDROUP, 2009). Para a formulação de rações por programação não linear, são necessários modelos matemáticos para predição do desempenho em função de variáveis conhecidas pelos nutricionistas como níveis nutricionais, sexo, idade, temperatura ambiente, densidade de alojamento e local de criação (EITS et al., 2005b). Portanto, a busca pelo aumento da produtividade e do lucro impõe desafios aos nutricionistas para que se formulem rações com uma boa relação entre custo e benefício (ARAUJO et al., 2011). A programação não linear pode ajudar nesta tarefa. 


\section{REVISÃO DA LITERATURA}

Programação linear para formulação de rações

A formulação de rações é o processo pelo qual diferentes ingredientes são combinados para suprir a necessidade nutricional dos animais em diferentes estágios de produção. Para a formulação de rações, é necessário conhecimento sobre exigências nutricionais, composição nutricional dos ingredientes e de técnicas de formulação de rações (SAXENA, 2011b).

Sobre composição nutricional dos ingredientes e exigências nutricionais, pode-se utilizar informações de artigos científicos, de manuais de manejo, de livros, de tabelas de exigências e da própria indústria. No Brasil, as Tabelas Brasileiras para Aves e Suínos Composição de Alimentos e Exigências Nutricionais é uma importante obra sobre o assunto (ROSTAGNO et al., 2011).

Em relação às técnicas de formulação, a programação linear é uma área da matemática que tem auxiliado na compreensão e no aprimoramento da nutrição animal. Trata-se de um método matemático de otimização de problemas sujeitos às restrições lineares com a finalidade de se obter uma solução ótima para uma função objetivo linear. Por meio da programação linear, é possível formular rações que atendam a exigência nutricional com o menor custo possível.

A programação linear foi utilizada de forma significativa, pela primeira vez, durante a Segunda Guerra Mundial para a determinação da estratégia mais eficaz na implantação das tropas, munições e maquinários (CASTRO et al., 2007). Na indústria avícola, os primeiros esforços para inserir a programação linear ocorreram na década de 50, mas o uso foi limitado, pois os nutricionistas não estavam treinados e tinham pouco ou nenhum conhecimento sobre o uso de computadores. O avanço deste método na avicultura foi possível devido ao desenvolvimento de pesquisas sobre informações nutricionais e pelo rápido desenvolvimento tecnológico experimentado nas últimas décadas (BALDWIN, 1995; OVIEDO-RONDÓN; WALDROUP, 2002; SAKOMURA; LONGO; OVIEDO-RONDÓN, 2005; MCNAMARA, 2006).

A técnica de formulação de rações utilizando a programação linear permite encontrar a combinação de ingredientes que atenda a exigência nutricional para maximizar o desempenho, alcançando os melhores resultados referentes ao preço da ração durante o processo, que é o mínimo custo (ZHANG; ROUSH, 2002; AL DESEIT, 2009; CERRATE; WALDROUP, 2009; NABASIRYE et al., 2011; SAXENA, 2011a, 2011b; KIDD et al., 2013). 
Pode-se, então, elaborar um modelo matemático linear que represente o problema de formulação de ração, que é constituído pela função objetivo e pelas restrições (SAXENA, 2011a). Em seguida, com o uso do algoritmo Simplex ${ }^{\circledR}$ a solução ótima é encontrada, ou seja, a ração de custo mínimo (FARIA FILHO et al., 2008; ARAÚJO, 2012). Neste caso, a computação é um facilitador para a elaboração dos cálculos, oferecendo agilidade operacional no processo de formulação (GHOSH et al., 2014).

O modelo matemático da programação linear para a formulação de rações segue uma estrutura contendo "n" variáveis de decisão e "m" restrições. Em termos algébricos, o modelo matemático da programação linear aplicada à formulação de ração é (Adaptada de GHOSH et al., 2014):

Função objetivo (Z):

$$
\mathrm{Z}=\sum_{\mathrm{j}=1}^{\mathrm{n}} \mathrm{c}_{\mathrm{j}} * \mathrm{x}_{\mathrm{j}}
$$

Sujeita às restrições:

$$
\begin{gathered}
\sum_{j=1}^{n} a_{i j} * x_{j}(\leq,=, \geq) b_{i} \text { para } i=1, \ldots, m ; x_{j} \geq 0 \\
\sum_{j=1}^{n} x_{j}=1
\end{gathered}
$$

Onde:

$\mathrm{Z}=$ preço total da ração. É a função objetivo que deve ser minimizada;

$\mathrm{c}_{\mathrm{j}}=$ preço por $\mathrm{Kg}$ de $\mathrm{j}^{\mathrm{n}}$ ingredientes;

$\mathrm{x}_{\mathrm{j}}=$ quantidade de $\mathrm{j}^{\mathrm{n}}$ ingredientes (variáveis de decisão);

$\mathrm{a}_{\mathrm{ij}}=$ quantidade do $\mathrm{i}^{\mathrm{m}}$ nutriente presente no $\mathrm{j}^{\mathrm{n}}$ ingrediente (matriz nutricional);

$b_{i}=$ quantidade requerida do $i^{m}$ nutriente na ração (exigência nutricional).

Os métodos lineares garantem melhor produtividade, mas não implicam necessariamente em máxima lucratividade, pois não permitem uma análise detalhada em relação aos aspectos econômicos da formulação de ração, trabalhando com exigências nutricionais fixas, não considerando o efeito das oscilações de mercado sobre as mesmas 
(GUEVARA, 2004; FARIA FILHO et al., 2008; CERRATE; WALDROUP, 2009; AFROUZIYEH et al., 2011; GARCIA NETO et al., 2011; DAHAB, 2015).

Por toda a complexidade das relações entre desempenho, exigências nutricionais, oscilações de preços dos ingredientes e do produto final, não é possível representar e resolver esse problema com a programação linear. Com isso, tem-se a programação não linear como alternativa, sendo um novo desafio na busca pelo máximo lucro da indústria avícola (SAXENA, 2011a).

Programação não linear para formulação de rações

A programação não linear é uma técnica matemática de otimização utilizada quando a função objetivo ou pelo menos uma das restrições envolvidas não são lineares (LACHTERMACHER, 2004; GHOSH, et al., 2014). Em formulação de rações, esta técnica possibilita incorporar a modelagem matemática, permitindo considerar, durante a formulação, as flutuações dos preços dos ingredientes, a variação do desempenho devido à diferença dos níveis nutricionais e o preço pago pelo kg do frango vivo, que serão capazes de determinar uma exigência nutricional para otimizar a lucratividade, alvo da indústria (FARIA FILHO et al., 2008; CERRATE; WALDROUP, 2010a, 2010b; ARAUJO et al., 2011; GARCIA NETO, 2011).

A modelagem matemática é utilizada para simular o desempenho em resposta a densidade nutricional (CERRATE; WALDROUP, 2010a, GARCIA NETO, 2011) e passou a ser incorporada a formulação de ração por volta de 1914 (DUMAS; DIJKSTRA; FRANCE, 2008). A relação entre o incremento de doses de nutrientes e a lucratividade está esquematizada na Figura 1 (EITS et al., 2005b). Com aumento das doses do nutriente, ocorre aumento da receita (entrada de capital), pois esse está relacionado com o aumento do desempenho do frango de corte. No entanto, o custo também se eleva com o incremento da dose do nutriente, porque o preço da ração aumenta. O lucro é calculado pela diferença entre receita e custo. Na Figura 1 estão destacados três pontos. Os níveis nutricionais do ponto 1 e do ponto 2 não promovem o máximo lucro. Os níveis nutricionais estabelecidos no ponto 2 são aqueles que geram máximo lucro, pois é no ponto 2 onde ocorre a maior diferença entre receita e custo. Portanto, quando se formula ração para otimizar o desempenho (ou receita), não se consegue o máximo lucro. Para realização desse tipo de análise é necessária a utilização de modelos matemáticos para previsão da receita e do custo em função da dose do nutriente. 
Figura 1 - Relação entre o incremento de doses de nutrientes e a lucratividade

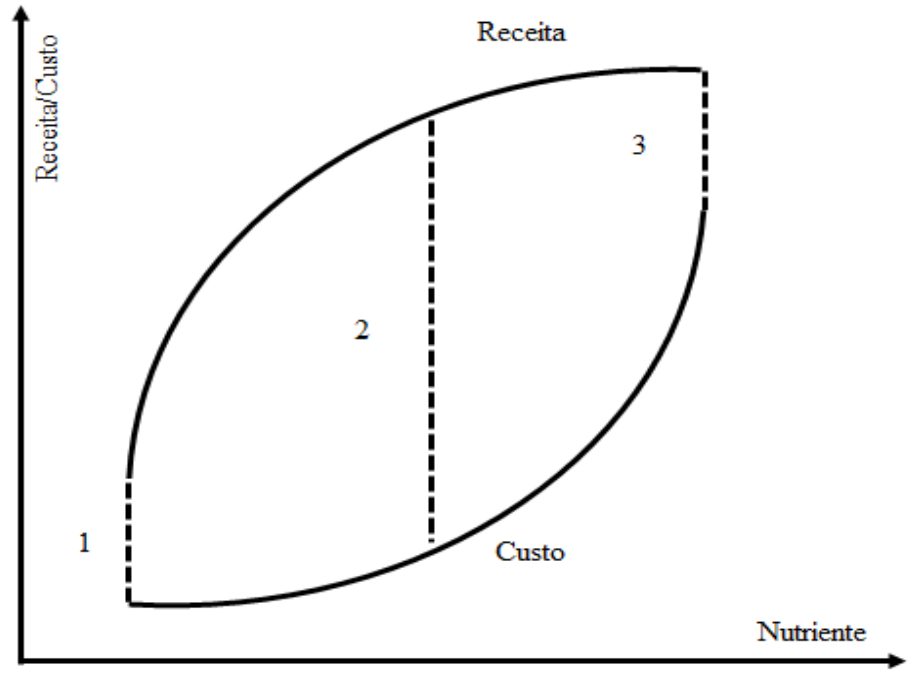

1: região de baixo custo, no entanto, a receita é baixa.

2: região de lucro máximo.

3: região de alta receita, no entanto, o custo é alto.

Fonte: Adaptado de EITS, R. M. et al. Dietary balanced protein in broiler chickens: an economic analysis. Bristish Poultry Science, Abingdon, v. 46, p. 310-317, 2005 b.

Atualmente os modelos matemáticos proporcionam praticidade e flexibilidade, incluindo variáveis conhecidas pelo nutricionista e que são determinantes para o desempenho e rentabilidade, tais como os níveis de energia metabolizável da ração (GUEVARA, 2004; MENDES et al., 2004; BARBOSA, 2008; ARAUJO et al., 2011; GONÇALVES et al., 2015), de proteína bruta (FARIA FILHO et al., 2008), sexo (LEANDRO et al., 2003; MENDES et al., 2004; GONÇALVES, et al., 2015), idade e temperatura ambiente (FARIA FILHO et al., 2008; ARAÚJO, 2011), dentre outras.

O modelo matemático da programação não linear para a formulação de rações tem pelo menos uma de suas restrições ou a função objetivo não linear. Guevara (2004) utilizou programação não linear para formulação de ração em um modelo em que a função objetivo não foi linear e incorporava o nível de energia metabolizável como variável de decisão. O autor estabeleceu o lucro (receita - custo) como função objetivo, para ser maximizada, e o nível de energia metabolizável era determinado por ocasião da formulação de ração. Para atingir tal objetivo incorporou-se na função objetivo um modelo matemático para prever o peso corporal e o consumo de ração em função da energia metabolizável. O modelo proposto por GUEVARA (2004) foi: 
Função objetivo:

$$
\mathrm{Z}=\left\{\left[\left(\mathrm{a} E M^{2}+\mathrm{b} E M+\mathrm{c}\right) \mathrm{xPPFV}\right]-\left[\left(\mathrm{d} E M^{2}+\mathrm{e} \mathrm{EM}+\mathrm{f}\right) \mathrm{xPPRA}\right]\right\}
$$

Onde:

$\mathrm{Z}=$ lucro calculado por meio da diferença entre receita e custo. A receita é dada por $\left[\left(\mathrm{a} E M^{2}+\mathrm{b} E M+\mathrm{c}\right) \times \mathrm{PPFV}\right]$ e o custo por $\left[\left(\mathrm{d} E M^{2}+\mathrm{e} E M+\mathrm{f}\right) \times \mathrm{PPRA}\right]$. É a função objetivo que deve ser maximizada;

Peso corporal $(\mathrm{kg})=\mathrm{a} E M^{2}+\mathrm{b} E M+\mathrm{c}$, onde $\mathrm{a}, \mathrm{b}, \mathrm{c}$ são parâmetros do modelo e EM representa o nível de energia metabolizável (Mcal/kg).

PPFV = preço pago pelo frango vivo $(\mathrm{R} \$ / \mathrm{kg})$. Variável de mercado.

Consumo de ração $(\mathrm{kg})=\mathrm{d} E M^{2}+\mathrm{e} E M+\mathrm{f}$, onde d, e, f são parâmetros do modelo e EM representa o nível de energia metabolizável (Mcal $/ \mathrm{kg}$ ).

PPRA = preço pago pela ração $(\mathrm{R} \$ / \mathrm{kg})$. Variável de mercado.

Nesse modelo, a função objetivo não é linear, portanto, sua otimização deve ser feita por técnicas da programação não linear. Os demais aspectos do modelo utilizado por Guevara (2004) foram semelhantes ao descrito para programação linear.

Modelos não lineares são mais complexos para serem implementados e, portanto, mais restritos em utilização, além de requererem maior conhecimento sobre os parâmetros matemáticos envolvidos. Há também maior morosidade computacional em relação à formulação linear, uma vez que os modelos são mais complexos (FERKET, 2011). Por outro lado, o uso da programação não linear na avicultura otimiza o emprego dos nutrientes preconizando a máxima lucratividade, promovendo diminuição da excreção de nutrientes e, consequentemente, menor impacto ambiental (PENZ JUNIOR; BRUNO; FIGUEIREDO, 2009; FERKET, 2011).

Revisão sistemática da literatura e metanálise

Os modelos matemáticos devem ser precisos e é desejável que sejam derivados de vários conjuntos de dados (EITS et al., 2005b). Para se obter um conjunto de dados da literatura científica pode-se utilizar a revisão sistemática de literatura que é capaz de selecionar adequadamente pesquisas relevantes (CASTRO et al., 2007). A revisão sistemática é uma 
técnica científica de revisar a literatura, utilizando métodos explícitos para identificar, selecionar e avaliar criticamente pesquisas relevantes. Dessa forma, ficam definidos previamente a estratégia de busca, as bases de dados, o período da revisão, os critérios para se manterem os artigos na revisão, entre outros. Todos esses aspectos devem ser mencionados no texto. Os estudos localizados, mas não incluídos, devem ser citados e sua exclusão justificada. Dessa forma, as revisões sistemáticas são reprodutíveis e normalmente não viesadas (CASTRO et al., 2007).

A metanálise combina resultados de vários estudos para fazer uma síntese reprodutível e quantificável dos dados (LOVATTO et al., 2007). Para isso, são necessários métodos estatísticos apropriados que são aplicados a dados já existentes na literatura a fim de se associarem os resultados de dois ou mais estudos, permitindo chegar-se a uma conclusão sobre o tema pesquisado. St-Pierre (2007) descreveu em detalhes os procedimentos estatísticos adequados para realização da metanálise que deve ser utilizada preferencialmente em dados provenientes de revisões sistemáticas, pois dessa forma se evita que a subjetividade do pesquisador interfira no resultado final da pesquisa.

Pesquisas de formulação de ração utilizando programação não linear

A programação não linear pode ser usada para definir a composição nutricional ideal que maximiza a margem de lucro da ração. Guevara (2004) desenvolveu uma estratégia de formulação de ração utilizando a programação não linear para otimizar o lucro na produção de frangos de corte a partir de cálculos baseados na variação do peso corporal e consumo de ração em função da densidade nutricional da ração, considerando variações de $\pm 25 \%$ nos preços de referência dos ingredientes e do preço pago pelo frango vivo. A programação não linear indicou que quando os preços dos ingredientes diminuíram, houve um aumento da densidade energética e o aumento do preço pago pelo frango vivo fez com que os níveis energéticos para otimização do lucro fossem maiores.

De maneira similar, Eits et al. (2005b), utilizando programação não linear, com base em modelos matemáticos preditivos de desempenho (EITS et al., 2005a), em resposta ao balanço proteico e, considerando variações de $\pm 20 \%$ ou de $\pm 40 \%$ sobre os preços de referência das variáveis econômicas, demonstraram que a concentração de proteína da ração é diferente da concentração alcançada para maximizar desempenho, porém é capaz de gerar máximo lucro.

Com o objetivo de demonstrar as interdependências entre custo, desempenho, preço pago pelo frango e níveis de lisina e de proteína bruta, Sterling et al. (2005) observaram que, 
com o aumento do preço da soja, os níveis de proteína bruta diminuíam e o máximo ganho de peso era garantido pelos níveis de lisina. Concluíram que a programação não linear conduz as rações que geram melhores lucros.

Dadalt et al. (2015) formularam rações por programação linear e não linear, sendo que esta última foi formulada utilizando o programa Camera ${ }^{\circledR}$ (Model Company Wala Group). Foram considerados na elaboração da fórmula por programação não linear a temperatura ambiente, a umidade relativa do ar, a velocidade do ar, a linhagem, o sexo, a densidade de alojamento, as fases de crescimento e o peso do frango. Os melhores resultados econômicos para frangos machos ocorreram em densidade de alojamento de 14 aves $/ \mathrm{m}^{2}$ e alimentados com rações elaboradas por formulação não linear. Ainda na formulação não linear com aves fêmeas alojadas em densidade de 10 aves $/ \mathrm{m}^{2}$ e alimentadas com rações com menores densidades nutricionais, houve uma redução no custo, embora apresentassem as piores conversões alimentares. No entanto, piores conversões alimentares não significam resultados econômicos negativos, pois o nível nutricional ótimo econômico não coincide com o ótimo para desempenho.

Gonçalves et al. (2015) desenvolveram modelos matemáticos para estimar o desempenho de frangos de corte em função do sexo, idade e densidade energética da ração, tendo utilizado a versão não linear do Programa Prático de Formulação de Ração (PPFR) (GARCIA NETO, 2010), que tem como base o modelo proposto por Guevara (2004). Os autores concluíram que a programação não linear estabelece níveis nutricionais que otimizam a lucratividade.

Em relação a poedeiras comerciais, Afrouziye et al. (2010) e Afrouziye et al. (2011) demonstraram vantagem da programação não linear na formulação de rações para poedeiras de 24 a 32 semanas de idade e de 32 a 44 semanas de idade, respectivamente. Esses autores utilizaram modelos matemáticos para previsão do desempenho em função do teor de energia metabolizável e variaram os preços pago para o ovo, milho e soja em $\pm 25 \%$ do preço referência. Os resultados indicaram que há vantagem econômica por meio do uso do modelo de programação não linear quando comparado a um modelo de programação linear com valores mínimos fixados para a energia. 


\section{REFERÊNCIAS}

AFROUZIYEH, M. et al. Use of nonlinear programming to determine the economically optimal energy density in laying hens diet during phase 1. African Journal of Agricultural Research, Victoria Island, v. 5, n. 20, p. 2770-2777, 2010.

AFROUZIYEH, M. et al. Use of nonlinear programming to determine the economically optimal energy density in laying hens diet during phase 2. Journal Applied of Poultry Research, Cary, v. 20, n. 1, p. 50-55, 2011.

AL-DESEIT, B. Least-cost broiler ration formulation using linear programming technique. Journal of Animal and Veterinary Advances, Faisalabad, v. 8, n. 7, p. 1274-1278, 2009.

ALMQUIST, H. J. Interpretation of amino acid requirement data according to the law of diminishing returns. Archives of Biochemistry and Biophysics, Maryland Heights, v. 44, n. 1, p. 245-247, 1953.

ARAÚJO, P. F. S. Programação linear e suas aplicações: definição e métodos de soluções. 2012. 74 f. Dissertação (Mestrado) - Instituto de Matemática e Estatística, Universidade Federal de Goiás, Goiânia, 2012.

ARAUJO, R. B. et al. Modelos de superfície de resposta para predição do desempenho de frangos e elaboração de análise econômica. Revista Brasileira de Saúde e Produção Animal, Salvador, v. 12, n. 3, p. 770-783, 2011.

ASSOCIAÇÃO BRASILEIRA DE PROTEÍNA ANIMAL. Relatório anual 2016. São Paulo: ABPA, 2015. Disponível em: <http://abpa-

br.com.br/storage/files/versao_final_para_envio_digital_1925a_final_abpa_relatorio_anual_2 016_portugues_web1.pdf>. Acesso em: 10 jun. 2016.

AVISITE. Ração altera radicalmente composição do custo de produção do frango. 2012. Disponível em: <http://www.avisite.com.br/noticias/index.php?codnoticia=13505>. Acesso em: 11 mar. 2015.

BARBOSA, F. J. V. et al. Níveis de energia metabolizável em rações para frangos de corte mantidos em ambiente de alta temperatura. Revista Brasileira de Zootecnia, Viçosa, v. 37, n. 5, p. 849-855, 2008.

CASTRO, A. A. et al. Curso de revisão sistemática e metanálise. São Paulo: LEDDIS/UNIFESP, 2007. Disponível em: <http://www.virtual.epm.br/cursos/metanalise>. Acesso em: 10 mar. 2015.

CENTRO DE ESTUDOS AVANÇADOS EM ECONOMIA APLICADA - CEPEA ESALQ/USP. Indicadores de preços. Piracicaba, 2016. Disponível em: <http://cepea.esalq.usp.br/indicador/>. Acesso em 10 mar. 2016.

CERRATE, S.; WALDROUP, P. Maximum profit feed formulation of broilers: 1. development of a feeding program model to predict profitability using non linear programming. International Journal of Poultry Science, Faisalabad, v. 3, n. 8, p. 205-215, 2009 . 
CERRATE, S.; WALDROUP, P. Maximum profit feed formulation. Interaction between energy content and temperature. International Journal of Poultry Science, Faisalabad, v. 7, n. 9, p. 634-640, 2010a.

CERRATE, S.; WALDROUP, P. Maximum profit feed formulation. Interaction between energy content and feed form. International Journal of Poultry Science, Faisalabad, v. 7, n. 9, p. 641-647, 2010b.

DADALT, J. C. et al. Comparison between linear and nonlinear systems of feed formulation for broilers. Brazilian Journal of Poultry Science, Campinas, v. 17, n. 1, p. 109-116, 2015.

DAHAB, M. Developing a generic decision support system for poultry feeding.

International Journal of Advances in Engineering Sciences, Rohtak, v. 5, n. 3, p. 32-37, 2015.

DUMAS, A.; DIJKSTRA, J.; FRANCE, J. Mathematical modelling in animal nutrition: a centenary review. Journal of Agricultural Science, Cambridge, v. 146, n. 2, p. 132-142, 2008.

EITS, R. M. et al. Dietary balanced protein in broiler chickens. 1. A flexible and practical tool to predict dose-response curves. British Poultry Science, Abingdon, v. 46, p. 300-309, 2005 a.

EITS, R. M. et al. Dietary balanced protein in broiler chickens. 2. An economic analysis. Bristish Poultry Science, Abingdon, v. 46, p. 310-317, 2005 b.

FARIA FILHO, D. E. et al. Response surface models to predict broiler performance and applications for economic analysis. Brazilian Journal of Poultry Science, Campinas, v. 10, n. 2, p. 131-138, 2008.

FERKET, P. R. Mechanistic modeling of turkey growth response to genotype and nutrition. Journal of Animal Science, Champaign, v. 89, p. 3170-3188, 2011.

GARCIA NETO, M. et al. Acurácia na formulação não-linear para frangos de corte: avanço e otimização de resultados. In: REUNIÃO ANUAL DA SOCIEDADE BRASILEIRA DE ZOOTECNIA, 48., 2011, Belém. Anais... Belém, PA, 2011.

GARCIA NETO, M. Programa Prático para Formulação e Otimização de Ração frangos de corte. Versão Excel 2010. Araçatuba, 2009. Disponível em:

<https://sites.google.com/site/ppfrparaexcel2007ousuperior/home>. Acesso em: 07 mar. 2015.

GHOSH, S. et al. Current concepts of feed formulation for livestock using mathematical modeling. Animal Nutrition and Feed Technology, Izatnagar, v. 14, n. 1, p. 205-223, 2014.

GONÇALVES, C. A. et al. Accuracy of nonlinear formulation of broiler diets: maximizing profits. Brazilian Journal of Poultry Science, Campinas, v. 17, n. 2, p. 173-180, 2015.

GOUS, R. M. Lysine: making progress in the nutrition of broilers. Poultry Science, Cary, v. 77, n. 1, p. 111-117, 1998. 
GUEVARA, V. R. Use of nonlinear programming to optimize performance response to energy density in broiler feed formulation. Poultry Science, Cary, n. 83, p. 147-151, 2004.

KIDD, M. T. et al. Feed-grade amino acid use in the United States: The synergetic inclusion history with linear programming. Journal of Applied Poultry Research, Cary, v. 3, n. 22, p. 583-590, 2013.

LACHTERMACHER, G. Pesquisa operacional na tomada de decisões. 2. ed. Rio de Janeiro: Campus, 2004. 384 p.

LEANDRO, N. S. M. et al. Plano nutricional com diferentes níveis de proteína bruta e energia metabolizável na ração para frangos de corte. Revista Brasileira de Zootecnia, Viçosa, v. 32, n. 3, p. 620-631, 2003.

LOVATTO, P. A. et al. Meta-análise em pesquisas científicas: enfoque em metodologias. Revista Brasileira de Zootecnia, Viçosa, v. 36, p. 285-294, 2007.

MCNAMARA, J. P. Mechanistic modelling at the metabolic level: a model of metabolism in the sow as an example. In: GOUS, R. M.; MORRIS, T. R.; FISHER, C. (Eds.) Mechanistic modeling in pig \& poultry production. Wallingford: CAB International, 2006, p. 282-304.

MENDES, A. A. et al. Efeitos da energia da dieta sobre desempenho, rendimento de carcaça e gordura abdominal de frangos de corte. Revista Brasileira de Zootecnia, Viçosa, v. 33, n. 6, p. 2300-2307, 2004.

NABASIRYE, M. et al. Optimization of input in animal production: a linear programming approach to the ration formulation problem. International Research Journal of Agricultura Science and Soil Science, Delta, v. 1, n. 7, p. 221-226, 2011.

OVIEDO-RONDÓN, E. O.; WALDROUP, P. W. Models to estimate amino acid requirements for broiler chickens: a review. International Journal of Poultry Science, Faisalabad, v. 1, n. 5, p. 106-113, 2002.

PENZ-JUNIOR, A.M.; BRUNO, D.; FIGUEIREDO, A. Nutrição de frangos: mudanças de paradigmas para o futuro. In: CONFERÊNCIA FACTA 2009 DE CIÊNCIA E TECNOLOGIA AVÍCOLAS, 2009, Porto Alegre. Anais... Porto Alegre, RS, 2009.

GARCIA NETO, M. et al. Acurácia na formulação não-linear para frangos de corte: avanço e otimização de resultados. In: REUNIÃO ANUAL DA SOCIEDADE BRASILEIRA DE ZOOTECNIA, 48., 2011, Belém. Anais... Belém, PA, 2011.

PEÑA, T.; LARA, P.; CASTRODEZA, C. Multiobjective stochastic programming for feed formulation. Journal of the Operational Research Society, London, v. 60, p. 1738-1748, 2009.

ROSTAGNO, H. S. et al. Tabelas brasileiras para aves e suínos: composição de alimentos e exigências nutricionais. 3. ed. Viçosa: UFV, 2011. 
SAKOMURA, N. K.; LONGO, F. A.; OVIEDO-RONDÓN, E. O. Modelling energy utilization in broiler chickens and growth parameter description. Poultry Science, Cary, n. 84, p. 1363-1369, 2005.

SAKOMURA, N. K.; ROSTAGNO, H.S. Métodos de pesquisa em nutrição de monogástricos. Jaboticabal: Funep, 2007. 283p.

SAXENA, P. Comparison of linear and nonlinear programming techniques for animal diet. Applied Mathematics, Greater Noida, p. 106-108, 2011a.

SAXENA, P. Application of nonlinear programming for optimization of nutrient requirements for maximum weight gain in buffaloes. International Journal of Food Science and Nutrition Engineering, Greater Noida, p. 8-10, 2011 b.

ST-PIERRE, N. R. Meta-analysis of experimental data in the animal science. Revista Brasileira de Zootecnia, Viçosa, v. 36, p. 343-358, 2007.

STERLING, K. G. et al. Economically optimal dietary crude protein and lysine levels for starting broiler chicks. Poultry Science, Cary, v. 84, p. 29-36, 2005.

UNIÃO BRASILEIRA DE AVICULTURA - UBABEF. Reunião anual 2014. São Paulo, 2012. Disponível em <http://www.ubabef.com.br/files/publicacoes/8ca705e70f0cb110ae3aed67d29c8842.pdf>. Acesso em: 27 jan. 2015.

VIEIRA, S. L.; STEFANELLO, C.; SORBARA, J. O. Formulating poultry diets based on their indigestible componentes. Poultry Science, Cary, v. 93, n. 9, p. 2411-2416, 2014.

ZHANG, F.; ROUSH, W. B. Multiple-objective (goal) programming model for feed formulation: an example for reducing nutrient variation. Poultry Science, Cary, n. 81, p. 182$192,2002$. 


\title{
CAPÍTULO 2
}

\section{FORMULAÇÃO DE RAÇÕES PARA FRANGOS DE CORTE USANDO PROGRAMAÇÃO LINEAR E NÃO LINEAR ${ }^{1}$}

\begin{abstract}
RESUMO
O uso da programação não linear em formulação de rações pode ser uma alternativa para a indústria avícola na busca pelo maior lucro. O objetivo deste estudo foi avaliar a formulação de rações utilizando a programação não linear sobre desempenho produtivo e econômico e sobre as características de carcaça de frangos de corte. Foram utilizados 1080 pintos de um dia, machos, da linhagem Cobb 500 ${ }^{\mathrm{TM}}$, distribuídos em delineamento em blocos casualizados com seis tratamentos e seis repetições de 30 aves cada. Três tratamentos consistiram em rações formuladas com programação linear utilizando exigências nutricionais das tabelas brasileiras, do manual da linhagem ou de modelos matemáticos para maximização do desempenho. Os outros três tratamentos foram com o uso da programação não linear para os cenários de mercado normal, favorável ou desfavorável. Foram avaliadas as características de desempenho e econômicas de 1 a 21 e de 1 a 42 dias e as características de carcaça aos 42 dias. Os tratamentos oriundos da programação linear promoveram melhores resultados de desempenho, dos quais a exigência obtida por modelos matemáticos se sobressaiu com melhor conversão alimentar em ambas as fases $(\mathrm{P}<0,001)$. Dentre as características de carcaça, os tratamentos da programação linear promoveram maiores rendimentos de carcaça, de peito e menores de dorso $(\mathrm{P}<0,001)$. Em termos de peso absoluto, maiores resultados de carcaça, peito, coxas+sobrecoxas, asas e dorso $(\mathrm{P}<0,001)$ foram observados pela programação linear. Por outro lado, a programação não linear revelou-se economicamente melhor por gerar menor custo de produção em ambas as fases em cenário de mercado favorável, que também apresentou a melhor lucro $(\mathrm{P}<0,001)$. Conclui-se que a programação linear gera rações que maximizam o desempenho e as características de carcaça, no entanto, a programação não linear possibilita a obtenção de rações que otimizam o lucro.
\end{abstract}

Palavras chave: Máximo lucro. Metanálise. Modelos matemáticos. Nutrição de precisão.

\footnotetext{
${ }^{1}$ Artigo submetido ao periódico Animal Journal (Fator de Impacto 1,841 - 2014).
} 


\section{ABSTRACT \\ FEED FORMULATION FOR BROILER CHICKENS USING LINEAR AND NON- LINEAR PROGRAMMING}

Non-linear programming applied to feed formulation may be an alternative to obtain higher profits in the poultry industry. This study aimed to evaluate the use of non-linear programming for feed formulation on the productive and economic performance and on the carcass characteristics of broiler chickens. It were used one thousand and eighty, one-day-old male broilers, Cobb 500 ${ }^{\mathrm{TM}}$ strain, distributed in randomized blocks, with six treatments and six replications with 30 chickens each. Three treatments were comprised by diets formulated using linear programming and employing nutritional requirements from Brazilian tables, strain handbook, and from mathematical models for the maximization of performance. The other three treatments were comprised by diets formulated using non-linear programming for the normal, favorable and unfavorable market scenarios. Performance and economic characteristics were evaluated from 1 to 21 days and from 1 to 42 days. The carcass characteristics were assessed at 42 days of age. Linear programming treatments had the best performance results, underscoring requirements obtained by mathematical models, with the best feed conversion in the two phases $(\mathrm{P}<0.001)$. In the case of carcass characteristics, linear programming treatments had the best carcass and breast rates and the lowest back rates $(\mathrm{P}<0.001)$. In absolute terms, diets formulated using linear programming generated the highest carcass, breast, thigh+drumstick, wings and back $(\mathrm{P}<0.001)$. On the other hand, non-linear programming was economically better in the two phases within a favorable market scenario $(\mathrm{P}<0.001)$. It was concluded that linear programming produces diets that maximize performance and carcarss characteristics, even though non-linear programming leads to better profit.

Keywords: Highest profit. Mathematical models. Meta-analysis. Precision nutrition. 


\section{IMPLICAÇÕES}

Nesta pesquisa se estuda um método de formulação de ração que usa a programação não linear para obtenção da ração de lucro máximo. As exigências de proteína bruta, de metionina+cistina digestível, de lisina digestível e de fósforo disponível são determinadas pelo programa computacional no momento da formulação de ração de acordo com as condições de mercado por ocasião da elaboração da fórmula. Com isso, o programa proposto para formulação de ração de lucro máximo é flexível e pode constituir em uma importante ferramenta na tomada de decisão de nutricionistas na otimização da lucratividade dos sistemas produtivos.

\section{INTRODUÇÃO}

A alimentação é o fator que mais onera o custo total de produção na cadeia de frangos de corte, representando mais de 50\% do custo total. Desde a década de 60 a programação linear tem sido aplicada na indústria de produção animal para otimizar os custos da alimentação (GHOSH et al., 2014). Hoje é a ferramenta mais difundida na indústria avícola para formular rações de custo mínimo. Por meio dessa técnica, é possível encontrar a mistura de ingredientes que atenda a exigência nutricional de determinada categoria animal com o menor custo possível (NABASIRYE et al., 2011; KIDD et al., 2013; VIEIRA et al., 2014). No entanto, a ração de custo mínimo pode não gerar o máximo lucro. A exigência nutricional para maximizar o lucro é menor do que aquela para otimização do desempenho (EITS et al., 2005) e, por meio da programação não linear, é possível formular rações considerando as oscilações de preços do mercado, tanto para ingredientes como para o preço pago pelo frango e, com isso, obter a ração de máximo lucro (GUEVARA, 2004; FARIA FILHO et al., 2008; CERRATE; WALDROUP, 2009). Nesse caso, a função objetivo e suas restrições perdem a linearidade, sendo necessária a aplicação da programação não linear que incorpora a modelagem matemática, possibilitando a predição do desempenho em função dos níveis nutricionais e de outras variáveis (EITS et al., 2005).

A programação não linear tem sido investigada na formulação de rações para frangos de corte, utilizando modelos matemáticos capazes de predizer desempenho em funções de variáveis tais como energia metabolizável (GUEVARA, 2004), proteína bruta, idade e temperatura (FARIA FILHO et al., 2008), energia metabolizável, idade e sexo (GONÇALVES et al., 2015), além de considerar as flutuações nos preços dos ingredientes. Os modelos desses estudos não foram aplicados experimentalmente, porém os resultados das simulações indicaram 
vantagem econômica sobre desempenho, pois tais modelos apresentaram capacidade de determinar a densidade nutricional mais lucrativa. Com isso, utilizando um modelo matemático considerando proteína bruta, metionina+cistina digestível, lisina digestível, fósforo disponível, sexo e local de criação em diferentes cenários de mercado, esse experimento teve por objetivo avaliar rações formuladas por programação não linear para obtenção do lucro máximo, sobre o desempenho produtivo, econômico e características de carcaça de frangos de corte.

\section{MATERIAL E MÉTODOS}

Os procedimentos experimentais adotados foram aprovados pela Comissão de Ética no Uso de Animais da Faculdade de Zootecnia e Engenharia de Alimentos (FZEA) da Universidade de São Paulo (USP), Campus Fernando Costa, Pirassununga, São Paulo, Brasil, sob protocolo número 5048060215.

Aves, delineamento experimental e manejo

O experimento foi realizado no setor de avicultura da FZEA/USP, de 1 de abril a 13 de maio de 2015. Foram utilizados 1080 pintos de um dia de idade, machos, da linhagem Cobb $500^{\mathrm{TM}}$, com peso inicial médio de 42,80 $\pm 0,71 \mathrm{~g}$, distribuídos em delineamento em blocos casualizados, com seis tratamentos, seis repetições de 30 aves cada. Os blocos foram utilizados para controlar diferenças de temperatura ao longo do galpão.

O galpão experimental foi de alvenaria fechado nas laterais com tela de arame galvanizado, coberto com telhas de fibrocimento e provido de cortinas nas laterais. Cada unidade experimental apresentava medidas de 1,5 $\mathrm{m}$ de largura por 2,0 $\mathrm{m}$ de comprimento totalizando $3 \mathrm{~m}^{2}$ de área de piso e gerando densidade de alojamento de $10 \mathrm{aves} / \mathrm{m}^{2}$. A cama foi de casca de arroz de terceira utilização com altura de aproximadamente $10 \mathrm{~cm}$. As aves foram vacinadas no incubatório contra as doenças de Marek e Gumboro. O aquecimento até o $10^{\circ}$ dia de vida foi feito com uma lâmpada infravermelho por unidade experimental, além de campânulas a gás distribuídas no corredor central do aviário. A partir do $11^{\circ}$ dia, o manejo de temperatura foi feito por meio da abertura e fechamento das cortinas e uso de ventiladores quando necessário. A temperatura registrada mínima, máxima e média foi de 20,5; 30,9 e $25,7^{\circ} \mathrm{C}$, respectivamente. A umidade relativa do ar registrada mínima, máxima e média foi de 28,6; 70,2 e 49,6\% respectivamente. Ração e água foram oferecidas ad libitum durante todo o período de criação. Os demais aspectos de manejo foram realizados seguindo o manual da linhagem Cobb 500 ${ }^{\mathrm{TM}}$ (COBB CONNECTION, 2012). 
Tratamentos experimentais

Os seis tratamentos experimentais foram: 1) ração formulada por programação linear, de custo mínimo, com exigências nutricionais de acordo Rostagno et al. (2011); 2) ração formulada por programação linear, de custo mínimo, com as exigências nutricionais recomendadas pelo manual da linhagem Cobb 500 ${ }^{\mathrm{TM}}$ (COBB CONNECTION, 2012); 3) ração formulada por programação linear, de custo mínimo, com as exigências nutricionais obtidas pela média da derivada parcial primeira igual a zero dos modelos matemáticos propostos por Saccomani et al. (2015) e Almeida et al. (2016) (Tabela 1) para consumo de ração e ganho de peso corporal; 4) ração formulada por programação não linear, de lucro máximo, em cenário de mercado normal; 5) ração formulada por programação não linear, de lucro máximo, em cenário de mercado favorável; e 6) ração formulada por programação não linear, de lucro máximo, em cenário de mercado desfavorável.

As rações de custo mínimo, dos tratamentos de 1 a 3, foram formuladas com ingredientes convencionais e com preço de março de 2015 para o Estado de São Paulo, Brasil, sendo: milho 0,17 US\$/kg, farelo de soja 0,38 US\$/kg, óleo de soja $0,99 \mathrm{US} \$ / \mathrm{kg}$, fosfato bicálcico 0,96 US\$/kg, calcário calcítico 0,07 US\$/kg, sal comum 0,08 US\$/kg, DL-metionina 13,47 US\$/kg, L-lisina 3,32 US\$/kg e premix 1,56 US\$/kg. Adotou-se o algoritmo Simplex, técnica da programação linear, para minimização da função objetivo que foi o preço da ração, sujeito as restrições: i) não negatividade para os ingredientes; ii) premix fixo em $0,4 \%$; iii) $100 \%$ para soma dos ingredientes; e iv) atendimento exato das exigências de energia metabolizável, proteína bruta, cálcio, fósforo disponível, sódio, metionina+cistina digestível e lisina digestível. Essas rações foram formuladas no Microsoft Excel ${ }^{\circledR}$, versão Professional Plus 2013, com auxílio do suplemento Solver ${ }^{\circledR}$ nas suas configurações default.

Os modelos matemáticos (Tabela 1) utilizados para determinação das exigências nutricionais dos tratamentos 3 ao 6 são modelos meta-analíticos, desenvolvidos a partir de 69 artigos científicos e 75 experimentos (SACCOMANI et al., 2015) e a partir de 72 artigos científicos e 81 experimentos (ALMEIDA et al., 2016), publicados no Brasil e no exterior. O consumo de ração $(\mathrm{g})$ e o ganho de peso $(\mathrm{g})$ foram as variáveis dependentes. Em Saccomani et al. (2015), para o período de 1 a 21 dias de idade, as variáveis independentes foram sexo (machos ou fêmeas), local de criação (piso ou gaiola), proteína bruta (15 a 24\%), metionina+cistina digestível (0,52 a 1,09\%), lisina digestível $(0,78$ a $1,31 \%)$ e fósforo disponível (0,10 a 0,65\%). Em Almeida et al. (2016), para o período de 22 a 42 dias de idade, as variáveis independentes foram sexo (machos ou fêmeas), local de criação (piso ou gaiola), 
proteína bruta (14 a 26\%), metionina+cistina digestível $(0,43$ a 1,10\%), lisina digestível $(0,56$ a $1,35 \%)$ e fósforo disponível $(0,10$ a $0,62 \%)$. Cada experimento entrou no modelo como variável aleatória e as variáveis independentes foram consideradas como de efeito fixo (STPIERRE, 2007). Os modelos foram ajustados por meio do PROC MIXED do SAS (LITTELL; STROUP; FREUND, 2002), com os parâmetros estimados pelo método da máxima verossimilhança, sendo mantidos os parâmetros com $\mathrm{P}<0,05$.

Para a formulação das rações de lucro máximo, dos tratamentos 4 a 6, adotaram-se os procedimentos descritos por Guevara (2004). Elaborou-se uma planilha no Microsoft Excel ${ }^{\circledR}$, versão Professional Plus 2013 e as configurações do suplemento Solver ${ }^{\circledR}$ foram: método de otimização = GRG não linear; derivativos = central; inicialização = início múltiplo; e demais configuração default. A função objetivo a ser maximizada foi a função de Lucro, calculada como a diferença entre a receita (GP x GP_Preço) e o custo [(CR x Preço_Ração)/0,70)], detalhada a seguir:

Lucro $($ US\$/frango $)=[($ GP x GP_Preço $)-($ CR x Preço_Ração $) / 0,70)]$

Onde:

$\mathrm{GP}=$ ganho de peso corporal $(\mathrm{kg})$. Essa variável foi calculada com a utilização do modelo matemático proposto por Saccomani et al. (2015) para 1 a 21 dias e por Almeida et al. (2016) para 22 a 42 dias de idade (Tabela 1), sendo, portanto, dependente do sexo, do local de criação e dos níveis dos nutrientes que fazem parte do modelo.

GP_Preço = preço pago pelo kg de frango vivo $(\mathrm{US} \$ / \mathrm{kg})$, sendo dependente do cenário de mercado no momento da formulação de ração.

$\mathrm{CR}$ = consumo de ração $(\mathrm{kg})$. Essa variável foi calculada usando o modelo matemático proposto por Saccomani et al. (2015) para 1 a 21 dias e por Almeida et al. (2016) para 22 a 42 dias de idade (Tabela 1), sendo, portanto, dependente do sexo, do local de criação e dos níveis dos nutrientes que fazem parte do modelo.

Preço_Ração = preço do $\mathrm{kg}$ da ração (US\$ $/ \mathrm{kg}$ ), sendo dependente do cenário de mercado no momento da formulação e é determinado no processo de formulação de ração.

$0,70=$ considera que o custo com alimentação representa $70 \%$ do custo total. 
Nesse processo de formulação de rações, as variáveis de decisão foram os ingredientes e os nutrientes que constam nos modelos matemáticos (Tabela 1). Dessa forma, durante o processo de formulação de ração, definem-se os níveis nutricionais que irão maximizar o lucro, além de se definir a ração. As seguintes restrições foram impostas ao modelo: i) não negatividade para os ingredientes; ii) premix fixo em 0,4\%; iii) $100 \%$ para soma dos ingredientes; iv) manteve-se a relação cálcio: fósforo disponível em 2:1; v) os níveis de energia metabolizável e de sódio foram estabelecidos de acordo com a exigência do manual da linhagem Cobb $500^{\mathrm{TM}}$ (COBB CONNECTION, 2012).

Para elaboração dos tratamentos de 4 a 6, utilizaram-se ingredientes convencionais, considerando como cenário de mercado normal aquele descrito anteriormente para o preço de ingredientes e o preço de 0,68 US\$ pago por kg de peso vivo. Para o cenário econômico favorável, o preço do milho e do farelo de soja foi diminuído em $10 \%$ e o preço pago pelo $\mathrm{kg}$ de frango vivo foi valorizado em 10\%. Para o cenário econômico desfavorável, o preço do milho e do farelo de soja foi aumentado em $10 \%$ e o preço pago pelo kg do frango vivo foi desvalorizado em 10\%. As rações experimentais para a fase de 1 a 21 dias de idade e para 22 a 42 dias de idade estão apresentadas nas Tabelas 2 e 3, respectivamente.

\section{Características avaliadas}

O desempenho produtivo foi avaliado de 1 a 21 dias de idade e de 1 a 42 dias de idade por meio do consumo de ração, ganho de peso, conversão alimentar, viabilidade criatória, índice de eficiência produtiva e uniformidade. A conversão alimentar foi calculada dividindo-se consumo de ração por ganho de peso e a viabilidade criatória foi calculada subtraindo-se de 100 a porcentagem de mortalidade. $\mathrm{O}$ índice de eficiência produtiva foi calculado pelo produto do ganho de peso médio diário pela viabilidade criatória dividido pelo produto da conversão alimentar por 10. A uniformidade foi obtida pela divisão entre o número de aves dentro da faixa de $\pm 10 \%$ do peso médio da parcela pelo número de aves na parcela multiplicado por 100 .

O desempenho econômico foi avaliado de 1 a 21 dias de idade e de 1 a 42 dias de idade por meio de US\$ gasto para produzir $1 \mathrm{~kg}$ de peso corporal. Adicionalmente, de 1 a 42 dias de idade, calculou-se o lucro tal qual descrito anteriormente.

O rendimento de carcaça, de cortes comerciais, de vísceras comestíveis e a gordura abdominal foram avaliados aos 42 dias de idade. Foram selecionadas cinco aves por unidade experimental com $\pm 5 \%$ do peso médio da parcela. As aves permaneceram em jejum alimentar por aproximadamente 6 horas, sendo posteriormente encaminhadas para o abatedouro, onde 
foram insensibilizadas por eletrochoque, abatidas por sangria, depenadas e evisceradas. Posteriormente, foram obtidos e pesados a carcaça, o peito, as coxas+sobrecoxas, as asas, o dorso, o coração, o fígado, a moela e a gordura abdominal. O rendimento de carcaça, das vísceras comestíveis e a gordura abdominal foram expressos em relação ao peso corporal. $\mathrm{O}$ rendimento dos cortes comerciais foi expresso em relação ao peso da carcaça fria.

\section{Análises estatísticas}

Os dados foram verificados quanto à presença de dados discrepantes e em seguida submetidos à análise de normalidade dos erros studentizados (teste de Cramer-Von-Mises) e de homogeneidade de variâncias (teste de Brown-Forsythe). Após constatado o atendimento das pressuposições de normalidade e homogeneidade de variâncias, os dados foram submetidos à análise de variância e, em caso de significância $(\mathrm{P}<0,05)$, aplicou-se o teste de Scott-Knott (SCOTT; KNOTT, 1974). As análises foram feitas com utilização do programa RStudio ${ }^{\circledR}$.

\section{RESULTADOS}

Os resultados de desempenho produtivo e econômico de 1 a 21 e de 1 a 42 dias de idade estão apresentados na Tabela 4. Não foram observadas diferenças estatísticas $(\mathrm{P}>0,05)$ para viabilidade criatória em ambos períodos e para uniformidade de 1 a 42 dias de idade.

No período de 1 a 21 dias, os tratamentos oriundos da programação linear resultaram em maior ganho de peso, seguidos pelos tratamentos Normal, Favorável e Desfavorável $(\mathrm{P}<0,001)$. Os tratamentos Rostagno e Cobb promoveram maiores valores de consumo de ração, seguidos pelo tratamento Modelos e Favorável que foram sucedidos pelos tratamentos Normal e Desfavorável, iguais entre si. O tratamento Modelos gerou melhores resultados de conversão alimentar e índice de eficiência produtiva, sobrevindo Rostagno e Cobb que foram seguidos pelo tratamento Normal e Favorável, e os piores resultados foram para o tratamento Desfavorável $(\mathrm{P}<0,001)$. A uniformidade dos lotes foi superior nos tratamentos da programação linear em relação a programação não linear $(\mathrm{P}<0,05)$. Por outro lado, o custo para produzir 1 kg de peso corporal foi maior em Rostagno e Desfavorável, na sequência de resultados decrescentes foram observados em Cobb, Modelos, Normal e Favorável $(\mathrm{P}<0,001)$ diferentes entre si.

No período de 1 a 42 dias, os tratamentos oriundos da programação linear resultaram em maior ganho de peso, os tratamentos Normal e Desfavorável apresentaram resultados 
intermediários e o tratamento Favorável apresentou o menor resultado $(\mathrm{P}<0,001)$. O consumo de ração dos tratamentos Rostagno, Cobb, Normal e Favorável foi igual entre si e maior que o do tratamento Desfavorável que foi sucedido pelo tratamento Modelos. Os melhores resultados de conversão alimentar foram obtidos pelo tratamento Modelos, seguido por Rostagno, que foi sucedido por Cobb, sendo que os tratamentos da programação não linear, iguais entre si, apresentaram os piores resultados. Os maiores índices de eficiência produtiva foram obtidos pelos tratamentos Modelos e Rostagno, sucedidos por Cobb, e os tratamentos da programação não linear, iguais entre si, apontaram os piores resultados $(\mathrm{P}<0,001)$. Por outro lado, o custo para produzir $1 \mathrm{~kg}$ de peso corporal foi mais elevado em Modelos, seguido por Rostagno e depois pelos os tratamentos Cobb e Desfavorável, seguidos pelo Normal. O tratamento Favorável apresentou o menor custo de produção. Em relação ao lucro, o tratamento Desfavorável apresentou o pior resultado, com os resultados melhorando para o tratamento Modelos, sucedido pelos tratamentos Rostagno e Cobb, iguais entre si, seguidos ainda pelo tratamento Normal e o melhor resultado para o tratamento Favorável $(\mathrm{P}<0,001)$.

Os resultados de características de carcaça estão apresentados na Tabela 5. Em termos relativos, não existiram diferenças entre os tratamentos $(\mathrm{P}>0,05)$ para coxas+sobrecoxas, asas, coração, fígado, moela e gordura abdominal. Os tratamentos da programação linear promoveram valores superiores de rendimentos de peito $(\mathrm{P}<0,001)$ e inferiores de dorso $(\mathrm{P}<0,01)$, em relação à programação não linear. Em termo de peso absoluto, não houve diferenças entre os tratamentos para as variáveis coração, fígado, moela e gordura abdominal $(\mathrm{P}>0,05)$. Todos os tratamentos da programação linear promoveram os maiores pesos de carcaça, peito, coxas+sobrecoxas e asas, seguidos pelos tratamentos Normal e Favorável, e, na sequência, pelo tratamento Desfavorável $(\mathrm{P}<0,001)$. O peso absoluto do dorso foi maior nos tratamentos da programação linear, iguais entre si, seguidos pelos tratamentos da programação não linear, similares entre si $(\mathrm{P}<0,001)$. 
Tabela 1 - Parâmetros de regressão de modelos meta-analíticos para consumo de ração e ganho de peso de frangos de corte

\begin{tabular}{|c|c|c|c|c|c|c|c|c|c|c|c|c|}
\hline & \multicolumn{6}{|c|}{ Consumo de ração $(\mathrm{g})$} & \multicolumn{6}{|c|}{ Ganho de peso (g) } \\
\hline & \multicolumn{3}{|c|}{1 a 21 dias $^{1}$} & \multicolumn{3}{|c|}{22 a 42 dias $^{2}$} & \multicolumn{3}{|c|}{1 a $21 \operatorname{dias}^{1}$} & \multicolumn{3}{|c|}{22 a 42 dias $^{2}$} \\
\hline & $\mathrm{Par}^{3}$ & $\mathrm{SE}$ & P-valor & $\mathrm{Par}^{3}$ & $\mathrm{SE}$ & P-valor & $\mathrm{Par}^{3}$ & $\mathrm{SE}$ & P-valor & $\mathrm{Par}^{3}$ & $\mathrm{SE}$ & P-valor \\
\hline Intercepto & $-1866,3$ & 339,76 & $* * *$ & 1854,2 & 291,82 & $* * *$ & $-2828,5$ & 284,75 & $* * *$ & $-1368,7$ & 553,48 & * \\
\hline \multicolumn{13}{|l|}{ Sexo } \\
\hline Macho & 0 & - & & 0 & - & & 0 & - & & 0 & - & \\
\hline Fêmea & $-60,2$ & 9,67 & $* * *$ & $-371,5$ & 17,15 & $* * *$ & $-47,3$ & 8,10 & $* * *$ & $-256,2$ & 14,26 & $* * *$ \\
\hline \multicolumn{13}{|l|}{ Local de criação } \\
\hline Piso & - & - & NS & - & - & NS & - & - & NS & 0 & - & \\
\hline Gaiola & - & - & NS & - & - & NS & - & - & NS & $-162,8$ & 53,8449 & $* *$ \\
\hline \multicolumn{13}{|l|}{ Efeito linear } \\
\hline Proteína bruta & 82,0 & 25,48 & $* * *$ & - & - & NS & 83,4 & 21,31 & $* * *$ & 104,9 & 43,80 & $*$ \\
\hline Metionina+cistina $^{4}$ & 1045,2 & 353,24 & $* * *$ & - & - & NS & 1482,4 & 295,23 & $* * *$ & 1024,4 & 448,79 & $*$ \\
\hline Lisina $^{4}$ & 1618,8 & 490,90 & $* * *$ & 1333,3 & 542,06 & $*$ & 2330,6 & 411,38 & $* * *$ & 1874,9 & 560,82 & $* *$ \\
\hline Fósforo disponível & 2731,8 & 230,47 & $* * *$ & 3106,1 & 516,53 & $* * *$ & 2260,6 & 193,29 & $* * *$ & 2075,2 & 434,06 & $* * *$ \\
\hline \multicolumn{13}{|l|}{ Efeito quadrático } \\
\hline Proteína bruta & $-1,898$ & 0,6564 & $* * *$ & NS & - & NS & $-1,659$ & 0,5488 & $* *$ & $-2,313$ & 1,1194 & $*$ \\
\hline Metionina+cistina $^{4}$ & $-641,4$ & 216,79 & $* * *$ & NS & - & NS & $-852,8$ & 181,13 & $* * *$ & $-522,9$ & 304,84 & $*$ \\
\hline Lisina $^{4}$ & $-726,6$ & 224,42 & $* * *$ & $-733,4$ & 279,64 & $* *$ & $-1031,1$ & 188,03 & $* * *$ & $-892,50$ & 289,40 & $*$ \\
\hline Fósforo disponível & $-2715,6$ & 315,91 & $* * *$ & $-3644,8$ & 729,46 & $* * *$ & $-2267,4$ & 264,94 & $* * *$ & $-2537,9$ & 615,25 & $* * *$ \\
\hline
\end{tabular}

${ }^{1}$ Adaptado de Saccomani et al. (2015).

${ }^{2}$ Adaptado de Almeida et al. (2016).

${ }^{3} \mathrm{Par}=$ parâmetro

${ }^{4}$ Digestível.

NS: Não significativo, $\mathrm{P}>0,05$.

$*: \mathrm{P}<0,05$

$* *: \mathrm{P}<0,01$.

$* * *$ : $\mathrm{P}<0,001$ 
Tabela 2 - Rações experimentais para fase inicial (1 a 21 dias de idade)

\begin{tabular}{|c|c|c|c|c|c|c|}
\hline & \multicolumn{3}{|c|}{ Formulação por programação linear } & \multicolumn{3}{|c|}{ Formulação por programação não linear } \\
\hline & Rostagno $^{1}$ & $\mathrm{Cobb}^{2}$ & Modelos $^{3}$ & Normal $^{4}$ & Favorável $^{5}$ & Desfavorável $^{6}$ \\
\hline \multicolumn{7}{|l|}{ Ingredientes } \\
\hline Milho & 53,17 & 56,01 & 48,09 & 52,56 & 51,43 & 54,13 \\
\hline Farelo de soja $45 \%$ & 38,94 & 35,57 & 42,06 & 39,77 & 40,38 & 39,05 \\
\hline Óleo de soja & 3,75 & 4,28 & 5,66 & 4,53 & 4,81 & 4,11 \\
\hline Calcário calcítico & 0,91 & 0,88 & 1,02 & 0,80 & 0,86 & 0,70 \\
\hline Fosfato bicálcico & 1,74 & 1,77 & 2,05 & 1,04 & 1,56 & 1,10 \\
\hline Cloreto de sódio & 0,51 & 0,46 & 0,46 & 0,46 & 0,46 & 0,46 \\
\hline DL-metionina $98 \%$ & 0,33 & 0,28 & 0,23 & 0,04 & 0,07 & 0,01 \\
\hline L-lisina $\mathrm{HCl} 78 \%$ & 0,22 & 0,31 & 0,00 & 0,00 & 0,00 & 0,00 \\
\hline Cloreto de colina $60 \%$ & 0,03 & 0,03 & 0,03 & 0,03 & 0,03 & 0,03 \\
\hline Premix $^{7}$ & 0,40 & 0,40 & 0,40 & 0,40 & 0,40 & 0,40 \\
\hline Total & 100 & 100 & 100 & 100 & 100 & 100 \\
\hline \multicolumn{7}{|l|}{ Composição calculada } \\
\hline Energia metabolizável & 3005 & 3072 & 3072 & 3072 & 3072 & 3072 \\
\hline Proteína bruta & 21,80 & 20,50 & 22,81 & 22,13 & 22,31 & 21,92 \\
\hline Fósforo disponível & 0,44 & 0,44 & 0,50 & 0,38 & 0,41 & 0,32 \\
\hline Cálcio & 0,88 & 0,87 & 1,00 & 0,76 & 0,82 & 0,65 \\
\hline Sódio & 0,22 & 0,20 & 0,20 & 0,20 & 0,20 & 0,20 \\
\hline Metionina+cistina digestível & 0,92 & 0,84 & 0,84 & 0,64 & 0,67 & 0,61 \\
\hline Lisina digestível & 1,27 & 1,26 & 1,17 & 1,12 & 1,14 & 1,11 \\
\hline Preço $(\$ / \mathrm{kg})$ & 0,3317 & 0,3261 & 0,3357 & 0,2920 & 0,2785 & 0,3026 \\
\hline
\end{tabular}

${ }^{1}$ Requerimento nutricional de acordo com Rostagno et al. (2011). ${ }^{2}$ Requerimento nutricional de acordo com Guia de Manejo Cobb ${ }^{\text {TM }} .{ }^{3}$ Requerimento nutricional obtido pela derivada parcial primeira dos modelos (Table1). ${ }^{4}$ Cenário de mercado normal de março de 2015 em São Paulo/Brasil para preço do milho, do farelo de soja e do preço pago pelo frango vivo. ${ }^{5}$ Cenário de mercado $10 \%$ melhor em relação ao normal. ${ }^{6}$ Cenário de mercado $10 \%$ pior em relação ao normal.

${ }^{7}$ Níveis por kg de produto: vitamina A 1.500.000,00 UI/kg; vitamina D3 500.000 UI/kg; vitamina E 2.500,00 UI/kg; vitamina K3 400,00 mg/kg; vitamina B1 $350,00 \mathrm{mg} / \mathrm{kg}$; vitamina B2 1.000,00 mg/kg; vitamina B6 500,00 mg/kg; vitamina B12 2.500,00 mcg/kg; niacina 7.500,00 mg/kg; ácido pantotênico 2.750 $\mathrm{mg} / \mathrm{kg}$; ácido fólico 150,00 mg/kg; Cu 25,00 g/kg; Fe 12,50 g/kg; Mn 17,50 g/kg; Zn 12,50 g/kg; I 300,00 mg/kg; Se 50,00 mg/kg; salinomicina 16,50 g/kg; virginiamicina $4,125 \mathrm{mg} / \mathrm{kg}$. 
Tabela 3 - Rações experimentais para fase de crescimento ( 22 a 42 dias de idade)

\begin{tabular}{|c|c|c|c|c|c|c|}
\hline & \multicolumn{3}{|c|}{ Formulação por programação linear } & \multicolumn{3}{|c|}{ Formulação por programação não linear } \\
\hline & Rostagno $^{1}$ & $\mathrm{Cobb}^{2}$ & Modelos $^{3}$ & Normal $^{4}$ & Favorável $^{5}$ & Desfavorável $^{6}$ \\
\hline \multicolumn{7}{|l|}{ Ingredientes } \\
\hline Milho & 59,84 & 61,70 & 46,93 & 68,99 & 66,49 & 68,99 \\
\hline Farelo de soja $45 \%$ & 31,81 & 30,16 & 42,02 & 25,57 & 27,71 & 25,57 \\
\hline Óleo de soja & 4,95 & 4,71 & 7,35 & 3,08 & 3,50 & 3,08 \\
\hline Calcário calcítico & 0,85 & 0,80 & 0,87 & 0,57 & 0,57 & 0,57 \\
\hline Fosfato bicálcico & 1,21 & 1,50 & 1,62 & 0,82 & 0,81 & 0,82 \\
\hline Cloreto de sódio & 0,46 & 0,43 & 0,43 & 0,43 & 0,43 & 0,43 \\
\hline DL-metionina $98 \%$ & 0,27 & 0,22 & 0,38 & 0,11 & 0,10 & 0,11 \\
\hline L-lisina $\mathrm{HCl} 78 \%$ & 0,22 & 0,07 & 0,00 & 0,02 & 0,00 & 0,02 \\
\hline Premix $^{7}$ & 0,40 & 0,40 & 0,40 & 0,40 & 0,40 & 0,40 \\
\hline Total & 100 & 100 & 100 & 100 & 100 & 100 \\
\hline \multicolumn{7}{|c|}{ Composição calculada (as-fed basis) } \\
\hline Energia metabolizável & 3175 & 3180 & 3180 & 3180 & 3180 & 3180 \\
\hline Proteína bruta & 19,10 & 18,50 & 22,70 & 17,00 & 17,77 & 17,00 \\
\hline Fósforo disponível & 0,33 & 0,38 & 0,42 & 0,25 & 0,25 & 0,25 \\
\hline Cálcio & 0,71 & 0,76 & 0,84 & 0,50 & 0,50 & 0,50 \\
\hline Sódio & 0,20 & 0,19 & 0,19 & 0,19 & 0,19 & 0,19 \\
\hline Metionina+cistina digestível & 0,80 & 0,74 & 0,98 & 0,60 & 0,60 & 0,60 \\
\hline Lisina digestível & 1,10 & 0,95 & 1,17 & 0,80 & 0,84 & 0,80 \\
\hline Preço $(\$ / \mathrm{kg})$ & 0,3158 & 0,3021 & 0,3659 & 0,2576 & 0,2423 & 0,2773 \\
\hline
\end{tabular}

${ }^{1}$ Requerimento nutricional de acordo com Rostagno et al. (2011). ${ }^{2}$ Requerimento nutricional de acordo com Guia de Manejo Cobb ${ }^{\circledR} .{ }^{3}$ Requerimento nutricional obtido pela derivada parcial primeira dos modelos (Table1). ${ }^{4}$ Cenário de mercado normal de março de 2015 em São Paulo/Brasil para preço do milho, do farelo de soja e do preço pago pelo frango vivo. ${ }^{5}$ Cenário de mercado $10 \%$ melhor em relação ao normal. ${ }^{6}$ Cenário de mercado $10 \%$ pior em relação ao normal.

${ }^{7}$ Níveis por kg de produto: vitamina A 2.044.800,00 UI/kg; vitamina $\mathrm{D}_{3} 508.360,00 \mathrm{UI} / \mathrm{kg}$; vitamina E 3.825,00 UI/kg; vitamina $\mathrm{K}_{3} 688,40 \mathrm{mg} / \mathrm{kg}$; vitamina $\mathrm{B}_{1}$ 494,80 mg/kg; vitamina $B_{2} 1.260,00 \mathrm{mg} / \mathrm{kg}$; vitamina $B_{6} 551,25 \mathrm{mg} / \mathrm{kg}$; vitamina $B_{12} 3.380,00 \mathrm{mcg} / \mathrm{kg}$; niacina 6.996,00 mg/kg; ácido pantotênico 2.866,50 mg/kg; ácido fólico 200,00 mg/kg; colina 60,00 g/kg; Cu 3.000,00 mg/kg; Fe 9.525,00 mg/kg; Mn 13,50 g/kg; Zn 12,50 g/kg; I 300,00 mg/kg; Se 75,65 mg/kg; salinomicina 10,50 g/kg; ácido-3-nitro 12,54 g/kg; haquinol 7.500,00 mg/kg. 
Tabela 4 - Desempenho econômico e produtivo de frangos de corte alimentados com rações formuladas por programação linear e não linear

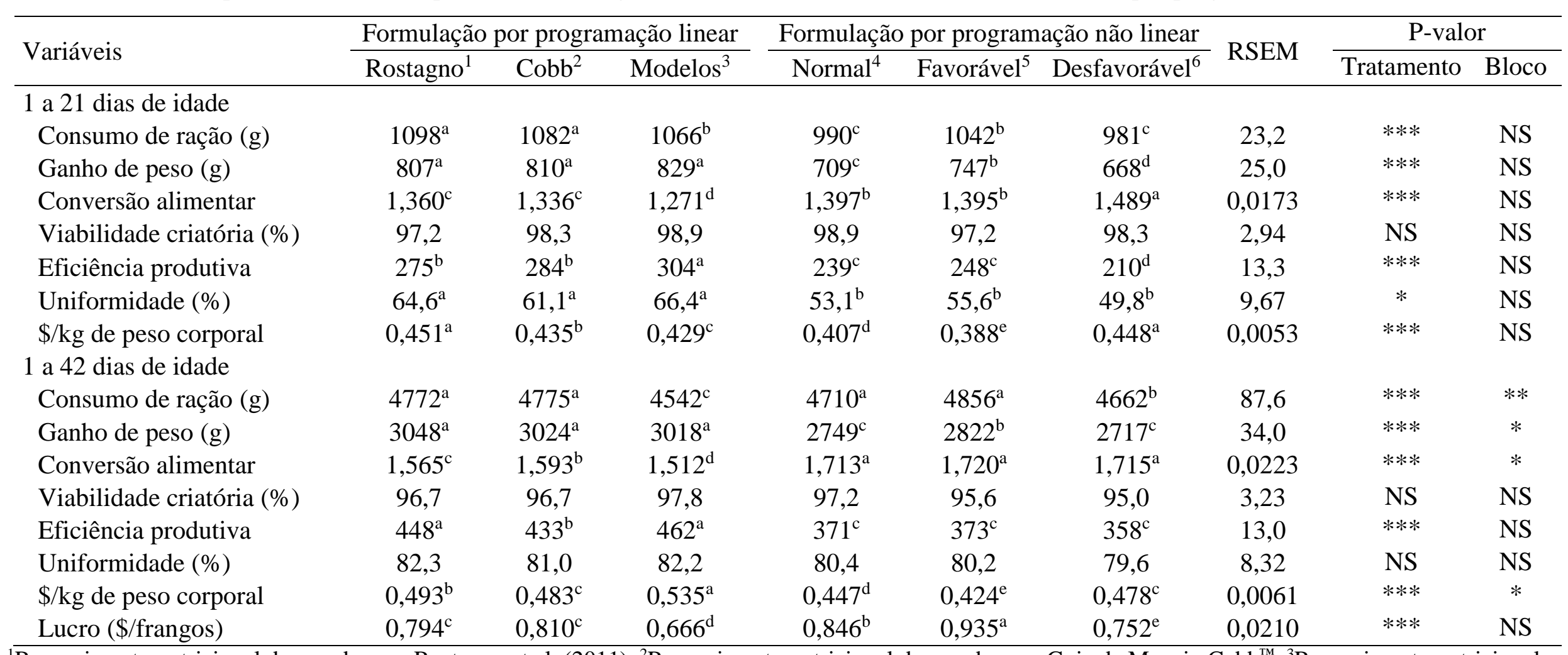

${ }^{1}$ Requerimento nutricional de acordo com Rostagno et al. (2011). ${ }^{2}$ Requerimento nutricional de acordo com Guia de Manejo Cobb ${ }^{\text {TM }} \cdot{ }^{3}$ Requerimento nutricional obtido pela derivada parcial primeira dos modelos (Tabela 1). ${ }^{4}$ Cenário de mercado de março de 2015 em São Paulo/Brasil para preço do milho, do farelo de soja e do preço pago pelo frango vivo. ${ }^{5}$ Cenário de mercado $10 \%$ melhor em relação ao normal. ${ }^{6}$ Cenário de mercado $10 \%$ pior em relação ao normal. a,b,c,d,e Valores na linha com diferentes sobrescritos diferem significativamente em $\mathrm{P}<0,05$ pelo teste de Scott-Knott.

NS: Não significativo, $\mathrm{P}>0,05 . *$ : $\mathrm{P}<0,05 . * *: \mathrm{P}<0,01 . * * *$ : $\mathrm{P}<0,001$. 
Tabela 5 - Características de carcaça aos 42 dias de frangos alimentados com rações formuladas por programação linear e não linear

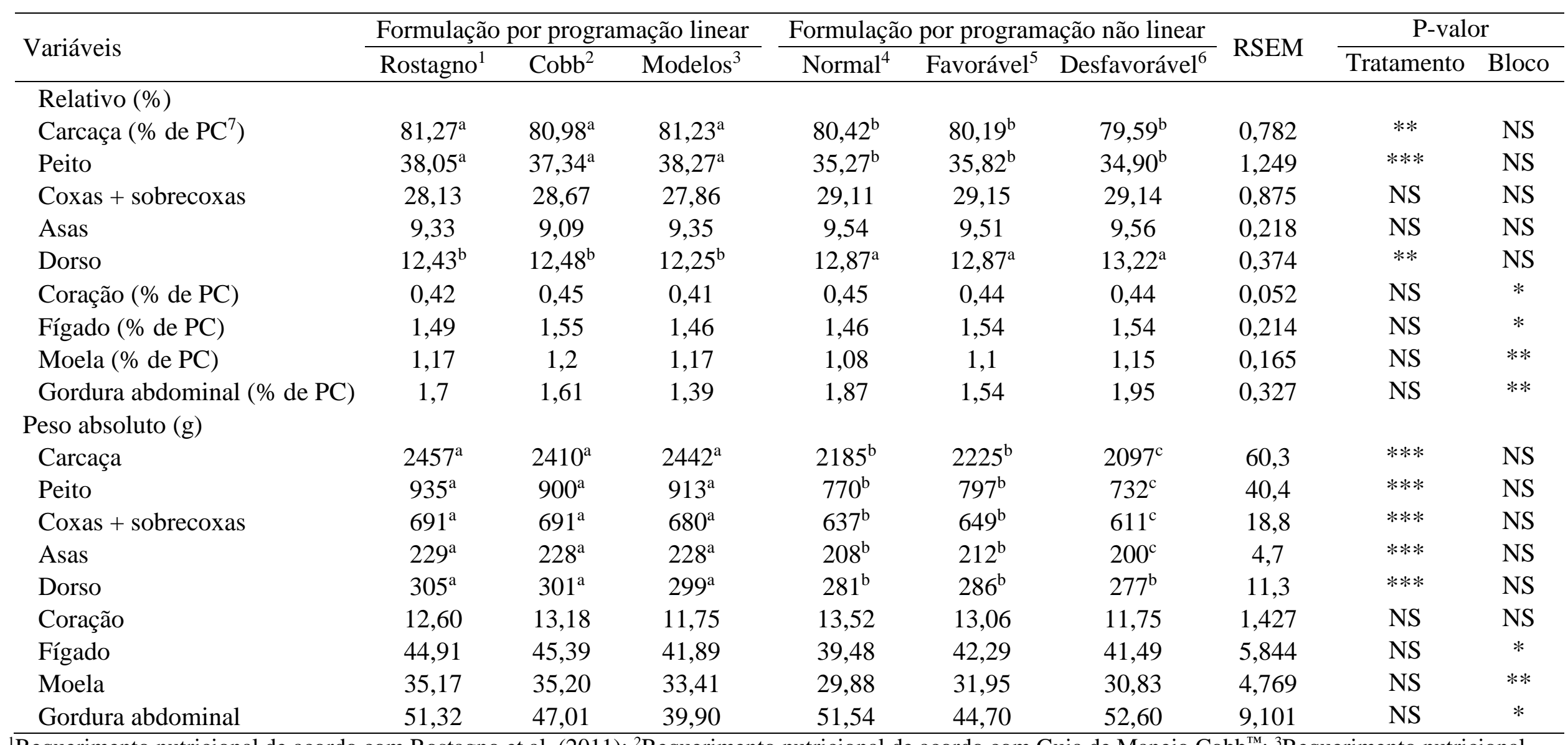

${ }^{1}$ Requerimento nutricional de acordo com Rostagno et al. (2011); ${ }^{2}$ Requerimento nutricional de acordo com Guia de Manejo Cobb ${ }^{\text {TM }} ;{ }^{3}$ Requerimento nutricional obtido pela derivada parcial primeira dos modelos (Tabela 1); ${ }^{4}$ Cenário de mercado de março de 2016 em São Paulo/Brasil para preço do milho, do farelo de soja e do preço pago pelo frango vivo. ${ }^{5}$ Cenário de mercado $10 \%$ melhor em relação ao normal. ${ }^{6}$ Cenário de mercado $10 \%$ pior em relação ao normal. ${ }^{7}$ Peso Corporal.

a,b,c Valores na linha com diferentes sobrescritos diferem significativamente em $\mathrm{P}<0,05$ pelo teste de Scott-Knott.

NS: Não significativo, $\mathrm{P}>0,05 . *$ : $\mathrm{P}<0,05$. **: $\mathrm{P}<0,01$. ***: $\mathrm{P}<0,001$ 


\section{DISCUSSÃO}

De forma geral, os tratamentos da programação linear proporcionaram melhor desempenho e características de carcaça em relação aos da programação não linear. Esses resultados podem ser explicados pela concentração mais elevada de nutrientes das rações experimentais oriundas da programação linear (Tabelas 2 e 3).

Melhores resultados de desempenho, como também rendimento de peito, foram obtidos com elevados níveis de metionina+cistina digestível na fase inicial (ABDELMAKSOUD et al., 2010; YUAN et al., 2012), bem como na fase de crescimento (GOULART et al., 2011). A administração de diferentes teores de lisina na fase inicial (ABDEL-MAKSOUD et al., 2010; TRINDADE NETO et al., 2011; OLIVEIRA et al., 2013) e na de crescimento (BERNAL et al., 2014; CARLOS et al., 2014), apontaram que os maiores valores do referido aminoácido estavam associados com o máximo desempenho e rendimento de peito, corroborando com os resultados deste estudo. Os resultados superiores de desempenho e rendimento de carcaça e de peito, nos tratamentos da programação linear e também maiores pesos absolutos de carcaça e suas partes, possivelmente são explicados pelo fato de a lisina ser considerada o principal aminoácido envolvido na síntese de proteína muscular e deposição nos tecidos (BERRI; BESNARD; RELANDEAU, 2008). Os níveis de cálcio e fósforo foram mais baixos nas rações formuladas por programação não linear, embora mantiveram a proporção 2:1, a qual é importante para manter o desempenho das aves (VEUM, 2010; MELLO et al., 2012a, 2012b).

A programação não linear, apesar de apresentar desempenho inferior, gerou maior lucro, corroborando com Eits et al. (2005) ao observarem que os níveis nutricionais que maximizam o lucro não coincidem com os níveis que promovem máximo desempenho. Leeson, Summers e Caston (2001) apontaram que rações com baixa densidade nutricional geram melhores resultados econômicos. Os resultados da presente pesquisa corroboram com Heydari (2014), Dadalt et al. (2015) e Gonçalves et al. (2015) ao evidenciarem que o maior desempenho obtido por rações formuladas pela programação linear não implica em máximo lucro do sistema de produção. Em estudos com poedeiras comerciais, Afrouziyeh et al. (2010) e Afrouziyeh et al. (2011) também observaram maior lucro utilizando a programação não linear para formular rações. 


\section{CONCLUSÃO}

Conclui-se, assim, que rações formuladas pela programação linear geram melhores resultados de desempenho e características de carcaça; no entanto, com o uso da programação não linear é possível maximizar o lucro do sistema produtivo por meio dos ajustes dos níveis nutricionais, conforme o cenário de mercado. A programação não linear é uma importante ferramenta que pode auxiliar o nutricionista na tomada de decisão, contribuindo para maior lucro do sistema de produção. 


\section{REFERÊNCIAS}

ABDEL-MAKSOUD, A. et al. Effect of dietary crude protein, lysine level and amino acid balance on performance of broiler 0 to 18 days of age. International Journal of Poultry Science, Faisalabad, v. 9, p. 21-27, 2010

AFROUZIYEH, M. et al. Use of nonlinear programming to determine the economically optimal energy density in laying hens diet during phase 1. African Journal of Agricultural Research, Victoria Island, v. 5, n. 20, p. 2770-2777, 2010.

AFROUZIYEH, M. et al. Use of nonlinear programming to determine the economically optimal energy density in laying hens diet during phase 2. Journal Applied of Poultry Research, Cary, v. 20, n. 1, p. 50-55, 2011.

ALMEIDA, T. W. et al. Meta-análise das exigências nutricionais de frangos de corte de 22 a 42 dias. In: CONFERÊNCIA APINCO DE CIÊNCIAS E TECNOLOGIA AVÍCOLA, 2016, Campinas. Anais... Campinas, SP, 2016.

BERNAL, L. E. P. et al. Digestible Lysine Requirements of Broilers. Brazilian Journal of Poultry Science, Campinas, v. 16, n. 1, p. 49-55, 2014.

BERRI, C.; BESNARD, J.; RELANDEAU, C. Increasing dietary lysine increases final pH and decreases drip loss of broiler breast meat. Poultry Science, Cary, v. 87, n. 3, p. 480-484, 2008.

CARLOS, T. C. F. et al. Evaluation of different digestible lysine levels for male broilers during the period of 18 to 40 days of age. Brazilian Journal of Poultry Science, Campinas, v. 16, n. 1, p. 83-88, 2014.

CERRATE, S.; WALDROUP, P. Maximum profit feed formulation of broilers: 1 . development of a feeding program model to predict profitability using non linear programming. International Journal of Poultry Science, Faisalabad, v. 3, n. 8, p. 205-215, 2009.

COBB CONNECTION. Manual de manejo de frangos de corte Cobb. Cobb-Vantress Inc. Siloam Springs, 2012.

DADALT, J. C. et al. Comparison between linear and nonlinear systems of feed formulation for broilers. Brazilian Journal of Poultry Science, Campinas, v. 17, n. 1, p. 109-116, 2015.

EITS, R. M. et al. Dietary balanced protein in broiler chickens. 2. An economic analysis. Bristish Poultry Science, Abingdon, v. 46, p. 310-317, 2005.

FARIA FILHO, D. E. et al. Response surface models to predict broiler performance and applications for economic analysis. Brazilian Journal of Poultry Science, Campinas, v. 10, n. 2, p. 131-138, 2008.

GHOSH, S. et al. Current concepts of feed formulation for livestock using mathematical modeling. Animal Nutrition and Feed Technology, Izatnagar, v. 14, n. 1, p. 205-223, 2014. 
GONÇALVES, C. A. et al. Accuracy of nonlinear formulation of broiler diets: maximizing profits. Brazilian Journal of Poultry Science, Campinas, v. 17, n. 2, p. 173-180, 2015.

GOULART, C. C. et al. Requirements of digestible methionine + cystine for broiler chickens at 1 to 42 days of age. Revista Brasileira de Zootecnica, Viçosa, v. 40, n. 4, p. 797-803, 2011.

HEYDARY, S. G. Effect of linear and random non-linear programming feed formulating on performance of broilers. Journal of Novel Applied Sciences, Sharja, v. 3, n. 12, p. 14261429, 2014.

GUEVARA, V. R. Use of nonlinear programming to optimize performance response to energy density in broiler feed formulation. Poultry Science, Cary, n. 83, p. 147-151, 2004.

KIDD, M. T. et al. Feed-grade amino acid use in the United States: The synergetic inclusion history with linear programming. Journal of Applied Poultry Research, Cary, v. 3, n. 22, p. 583-590, 2013.

LEESON, S.; SUMMERS, J. D.; CASTON, L. J. Response of layeres to low nutrient-density diets. Journal of Applied Poultry Research, Cary, v. 10, p. 46-52, 2001.

LITTELL, R. C.; STROUP, W. W.; FREUND, R. J. SAS for Linear Models. Cary: Statistical Analysis Systems Institute Inc., 2002.

MELLO, H. H. C. et al. Requirement of available phosphorus by female broiler chickens keeping the calcium:available phosphorus ratio at 2:1. Revista Brasileira de Zootecnia, Viçosa, v. 41, n. 11, p. 2329-2335, 2012a.

MELLO, H. H. C. et al. Dietary requirements of available phosphorus in growing broiler chickens at a constant calcium:available phosphorus ratio. Revista Brasileira de Zootecnia, Viçosa, v. 41, n. 11, p. 2323-2328, 2012 b.

NABASIRYE, M. et al. Optimization of input in animal production: a linear programming approach to the ration formulation problem. International Research Journal of Agricultura Science and Soil Science, Delta, v. 1, n. 7, p. 221-226, 2011.

OLIVEIRA, W. P. et al. Lysine levels in diets for broilers from 8 to 21 days of age. Revista Brasileira de Zootecnia, Viçosa, v. 42, n. 12, p. 869-878, 2013.

ROSTAGNO, H. S. et al. Tabelas brasileiras para aves e suínos: composição de alimentos e exigências nutricionais. 3. ed. Viçosa: UFV, 2011.

SACCOMANI, A. P. O. et al. Meta-análise das exigências nutricionais de frangos de corte de 1 a 21 dias. In: 52a REUNIÃO ANUAL DA SOCIEDADE BRASILEIRA DE ZOOTECNIA, 2015, Belo Horizonte. Anais... Belo Horizonte, MG, 2015.

SCOTT, A.; KNOTT, M. A. A cluster analysis method for grouping means in the analysis of variance. Biometrics, Chichester, v. 30, n. 3, 507-512, 1974. 
ST-PIERRE, N. R. Meta-analysis of experimental data in the animal science. Revista Brasileira de Zootecnia, Viçosa, v. 36, p. 343-358, 2007.

TRINDADE NETO, M. A. et al. Digestible lysine and organic zinc for male broiler from 1 to 11 days of age: performance and body composition. Revista Brasileira de Zootecnia, Viçosa, v. 40, n. 3, p. 602-608, 2011.

VEUM, T. L. Phosphorus and calcium nutrition. In: VITTI, D. M. S. S.; KEBREAB, E. (Org.). Phosphorus and calcium utilization and requirements in farm animals. Oxfordshire: UK, 2010. p. 94-111.

VIEIRA, S. L.; STEFANELLO, C.; SORBARA, J. O. Formulating poultry diets based on their indigestible componentes. Poultry Science, Cary, v. 93, n. 9, p. 2411-2416, 2014.

YUAN, J. et al. Evaluation of herbal methionine source in broiler diets. International Journal of Poultry Science, Faisalabad, v. 11, n. 4, p. 247-250, 2012. 


\section{ANEXO - Parecer consubstanciado da Comissão de Ética no Uso de Animais}

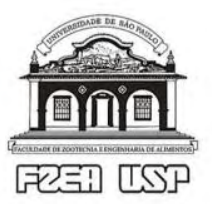

\author{
UNIVERSIDADE DESÃO PAULO \\ Faculdade de Zootecnia e Engenharia de Alimentos \\ Comitê de Ética em Pesquisa da FZEA
}

Pirassununga, 25 de abril de 2015 CEUA N 5048060215

IImo(a). Sr(a).

Responsável: Daniel Emygdio De Faria Filho

Depto/Disc: Zootecnia (zaz)

Pesquisadores envolvidos: Ariane Maria Leoni - executante (usp/fzea/pirassununga-sp); Thiago William De Almeida executante (usp/fzea/pirassununga-sp); Douglas Emygdio De Faria - colaborador (usp/fzea/pirassununga-sp); Daniel Emygdio De Faria Filho (orientador)

Título do projeto: "Revisão sistemática da literatura e metanálise com elaboração de modelos matemáticos para formulação não linear de ração para frangos de corte e poedeiras comerciais".

\section{Parecer Consubstanciado da Comissão de Ética no Uso de Animais FZEA}

Este projeto terá por objetivo elaborar revisões sistemáticas da literatura e metanálise com elaboração de modelos matemáticos para estimar as exigências nutricionais (energia metabolizável, proteína bruta, metionina, lisina, treonina, triptofano, valina, cálcio, fósforo disponível e sódio) para frangos de corte e poedeiras comerciais. Esses modelos serão utilizados para formular rações por procedimentos não lineares, ou seja, rações de máximo lucro ao invés de rações de custo mínimo. Para revisão sistemática será adotada a metodologia proposta por CASTRO et al. (2002) e aos dados coletados serão ajustados modelos de superfície de resposta (FREUND \& LITTELL, 2000). Nesses modelos serão adotadas como variáveis independentes os nutrientes mencionados anteriormente e a idade, a temperatura ambiente, a densidade de alojamento e sexo. As variáveis dependentes serão aquelas utilizadas para calcular o lucro, tais como consumo de ração, peso corporal, produção de ovos, conversão alimentar, entre outras. Será elaborado um programa de formulação não linear de ração no programa Excelß com auxílio do suplemento Solver ${ }^{\circledR}$ e das equações geradas no estudo. Esse programa de formulação determinará os níveis nutricionais e a ração de lucro máximo para diferentes cenários de mercado. Para elaboração desse programa serão utilizados os princípios estabelecidos por GUEVARA (2004). Esse programa será disponibilizado gratuitamente aos interessados. Serão conduzidos dois experimentos para comparação da formulação não linear de ração (lucro máximo) com a formulação linear de ração (custo mínimo), sendo um para frangos de corte e outro para poedeiras comerciais.

A Comissão de Ética no Uso de Animais da Faculdade de Zootecnia e Engenharia de Alimentos - FZEA/USP, na reunião de 25/02/2015, ANALISOU e APROVOU todos os procedimentos apresentados neste protocolo.

1. Comunicar toda e qualquer alteração do protocolo.

2. Comunicar imediatamente ao Comitê qualquer evento adverso ocorrido durante o desenvolvimento do protocolo.

3. Os dados individuais de todas as etapas da pesquisa devem ser mantidos em local seguro por 5 anos para possível auditoria dos órgãos competentes.

4. Relatórios parciais de andamento deverão ser enviados anualmente à CEUA até a conclusão do protocolo.

Atenciosamente,

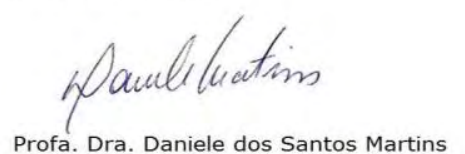

Coordenadora da Comissão de Ética no Uso de Animais

Faculdade de Zootecnia e Engenharia de Alimentos

Universidade de São Paulo 